\title{
LOSCAR: Long-term Ocean-atmosphere-Sediment CArbon cycle Reservoir Model v2.0.4
}

\author{
R. E. Zeebe \\ School of Ocean and Earth Science and Technology, University of Hawaii at Manoa, 1000 Pope Road, MSB 504, \\ Honolulu, 96822, USA
}

Correspondence to: R. E. Zeebe (zeebe@ soest.hawaii.edu)

Received: 24 May 2011 - Published in Geosci. Model Dev. Discuss.: 29 June 2011

Revised: 12 January 2012 - Accepted: 18 January 2012 - Published: 25 January 2012

\begin{abstract}
The LOSCAR model is designed to efficiently compute the partitioning of carbon between ocean, atmosphere, and sediments on time scales ranging from centuries to millions of years. While a variety of computationally inexpensive carbon cycle models are already available, many are missing a critical sediment component, which is indispensable for long-term integrations. One of LOSCAR's strengths is the coupling of ocean-atmosphere routines to a computationally efficient sediment module. This allows, for instance, adequate computation of $\mathrm{CaCO}_{3}$ dissolution, calcite compensation, and long-term carbon cycle fluxes, including weathering of carbonate and silicate rocks. The ocean component includes various biogeochemical tracers such as total carbon, alkalinity, phosphate, oxygen, and stable carbon isotopes. LOSCAR's configuration of ocean geometry is flexible and allows for easy switching between modern and paleo-versions. We have previously published applications of the model tackling future projections of ocean chemistry and weathering, $p \mathrm{CO}_{2}$ sensitivity to carbon cycle perturbations throughout the Cenozoic, and carbon/calcium cycling during the Paleocene-Eocene Thermal Maximum. The focus of the present contribution is the detailed description of the model including numerical architecture, processes and parameterizations, tuning, and examples of input and output. Typical CPU integration times of LOSCAR are of order seconds for several thousand model years on current standard desktop machines. The LOSCAR source code in C can be obtained from the author by sending a request to loscar.model@gmail.com.
\end{abstract}

\section{Introduction}

Various carbon cycle models that are computationally inexpensive have been developed in the past, in particular box models of the ocean's carbon cycle (e.g. Sarmiento and Toggweiler, 1984; Siegenthaler and Wenk, 1984; Walker and Kasting, 1992; Toggweiler, 1999; Stephens and Keeling, 2000; Köhler et al., 2005; Peacock et al., 2006). However, less studies have coupled a genuine sediment model to the ocean box model (e.g. Sundquist, 1986; Keir, 1988; Opdyke and Walker, 1992; Sigman et al., 1998; Ridgwell, 2001) and also considered long-term carbon cycle fluxes and feedbacks such as carbonate and silicate rock weathering (e.g. Munhoven and Francois, 1996; Shaffer et al., 2008). The LOSCAR model (Long-term Ocean-atmosphereSediment CArbon cycle Reservoir model) closes this gap. In addition, LOSCAR's configuration of ocean geometry is flexible (cf. Ridgwell, 2001) and allows for easy switching between modern and paleo-versions (see below). Note also that LOSCAR's sediment module includes variable porosity (Sect. 6.2). LOSCAR is primarily designed to efficiently compute the partitioning of carbon between ocean, atmosphere, and sediments on time scales ranging from centuries to millions of years. LOSCAR includes various biogeochemical tracers such as total dissolved inorganic carbon $\left(\mathrm{TCO}_{2}\right)$, total alkalinity (TA), phosphate $\left(\mathrm{PO}_{4}\right)$, oxygen $\left(\mathrm{O}_{2}\right)$, stable carbon isotopes $\left(\delta^{13} \mathrm{C}\right)$, and $\% \mathrm{CaCO}_{3}$ in sediments. Based on the predicted tracer distributions, different variables are computed including atmospheric $\mathrm{CO}_{2}$, ocean $\mathrm{pH}$, calcite and aragonite saturation state, calcite compensation depth (CCD) and more. LOSCAR also allows for changes in the major ion composition of seawater, including the seawater $\mathrm{Mg} / \mathrm{Ca}$ 
ratio, which is critical for paleo-applications. The major ion seawater composition affects thermodynamic quantities such as equilibrium constants and solubility products, which in turn affect the predicted ocean carbonate chemistry and atmospheric $\mathrm{CO}_{2}$.

We have previously published several applications of LOSCAR dealing, for instance, with future projections of ocean chemistry and weathering, $p \mathrm{CO}_{2}$ sensitivity to carbon cycle perturbations throughout the Cenozoic, and carbon/calcium cycling during the Paleocene-Eocene Thermal Maximum (PETM) (Zeebe et al., 2008; Zachos et al., 2008; Zeebe et al., 2009; Uchikawa and Zeebe, 2008; Stuecker and Zeebe, 2010; Uchikawa and Zeebe, 2010; Komar and Zeebe, 2011; Zeebe and Ridgwell, 2011; Zeebe, 2012). The subject of the present contribution is the detailed description of the model including numerical architecture, processes and parameterizations, tuning, and examples of input and output. It may appear that publishing model applications before a detailed model description is putting the cart before the horse. One of the reasons for this is that the journals interested in publishing the model applications have little or no interest in publishing a detailed model description. Journals that provide a forum for technical model descriptions are rare, and so the recent appearance of Geoscientific Model Development has encouraged me to provide a coherent model description of LOSCAR that will hopefully be useful for the readership of the journal, as well as the users of the model. On the other hand, publishing a few model applications before the detailed model description also has an advantage. LOSCAR, for example, has been extensively tested by now and several minor bugs and numerical issues have already been fixed (see Sect. 7.4).

LOSCAR's main components include ocean, atmosphere, and marine sediments. The model architecture, main components, model variables, and process parameterizations will be described in the following. Finally, two input/output examples will be presented, one dealing with anthropogenic fossil fuel emissions, the other with carbon release during the PETM (input files for these examples are included in the model package).

\section{Architecture}

The basic numerical architecture of the model is fairly simple. For all model variables $y_{i}$, i.e. all tracers in all compartments (atmosphere, ocean boxes, and sediment boxes), a system of coupled, first-order ordinary differential equations is solved:

$\frac{\mathrm{d} y_{i}}{\mathrm{~d} t}=F\left(t, y_{1}, y_{2}, \ldots, y_{\mathrm{NEQ}}\right)$,

where $t$ is time, NEQ is the total number of equations, $i=$ $1,2, \ldots, \mathrm{NEQ}$, and $F^{\prime} \mathrm{s}$ are known functions. Note that for most applications, the derivatives (right-hand side of Eq. 1) do not explicitly depend on the independent variable $t$. For

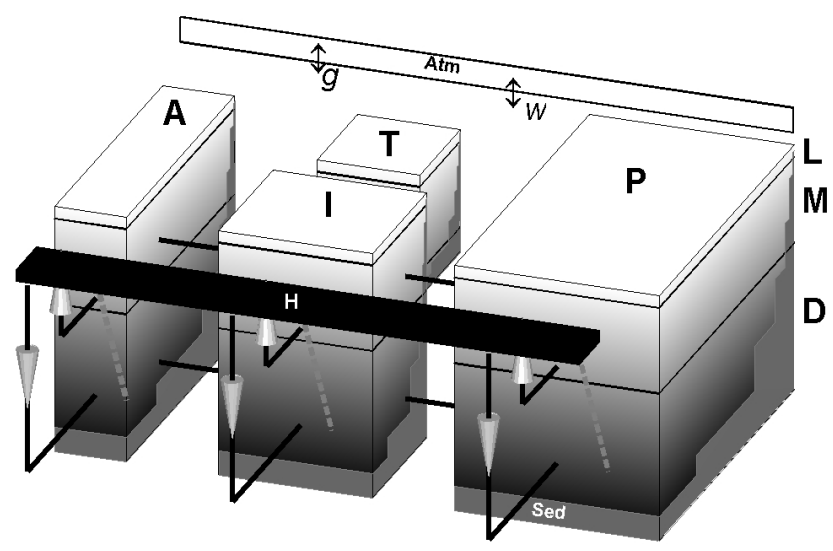

Fig. 1. Schematic representation of the LOSCAR model (Paleocene/Eocene configuration). $\mathrm{A}=$ Atlantic, $\mathrm{I}=$ Indian, $\mathrm{P}=$ Pacific, $\mathrm{T}=$ Tethys ocean, $\mathrm{H}=$ High-latitude surface, $\mathrm{L}=$ Low-latitude surface, $\mathrm{M}=$ interMediate, $\mathrm{D}=$ Deep box. Weathering fluxes and gas exchange with the atmosphere (Atm) are indicated by "w" and "g", respectively. Steps on the faces of ocean boxes indicate sediments (Sed).

given start (initial) conditions $\boldsymbol{y}_{0}$ at $t_{\text {start }}$, the equations are then integrated forward in time over the interval from $t_{\text {start }}$ to $t_{\text {final. }}$ Standard numerical procedures (solvers) for this sort of problem are available. One thing to keep in mind is that the equations solved in LOSCAR are typically stiff and involve different time scales, which requires a solver for stiff problems with adaptive stepsize control. The solver implemented in the $\mathrm{C}$ version of LOSCAR is a fourth-order Rosenbrock method with automatic stepsize adjustment (Press et al., 1992).

Once the initial conditions $\boldsymbol{y}_{0}$ and derivatives $F$ 's have been supplied, the solution of the problem is usually straightforward. However, setting up $\boldsymbol{y}_{0}$ and $F$ requires some work. In the following, the individual model components will be described and expressions will be given for individual $F$ 's that enter Eq. (1). The current setup includes two different model versions: a "modern" version and a Paleocene/Eocene version ("P/E"-version for short).

\section{Ocean}

\subsection{Geometry}

The global ocean is geometrically divided in LOSCAR into separate ocean basins representing Atlantic, Indian, and Pacific Ocean (plus Tethys in the P/E-version). In turn, each ocean basin is subdivided into surface, intermediate, and deep ocean (Fig. 1). In addition, the model includes a generic high-latitude box (H-box), representing cold surface waters without reference to a specific location (cf. Walker and Kasting, 1992; Toggweiler, 1999). As a result, the total number of ocean boxes is $\mathrm{NB}=10$ in the modern version and $\mathrm{NB}=13$ 
Table 1. Model-architecture and ocean geometry parameters.

\begin{tabular}{lllr}
\hline Parameter & Symbol & Value $^{\mathrm{a}}$ & Unit \\
\hline \# Ocean basins & NOC & $3(4)$ & - \\
\# Ocean tracers & NOCT & varies & - \\
\# Ocean boxes & NB & $10(13)$ & - \\
\# Atm. tracers & NATM & 1 or $2^{\mathrm{b}}$ & - \\
\# Sediment levels & NSD & 13 & - \\
\# Equations & NEQ & NOCT $\times$ NB + NATM + NOC $\times$ NSD & - \\
Total ocean volume & $V_{\text {oc }}$ & $1.29 \times 10^{18, c}$ & $\mathrm{~m}^{3}$ \\
Total ocean area & $A_{\text {oc }}$ & $3.49 \times 10^{14, c}$ & $\mathrm{~m}^{2}$ \\
$\%$ Area & $f_{\mathrm{A}}$ & $26,18,46,10^{\mathrm{d}}$ & $\%$ \\
$\%$ Area & $f_{\mathrm{A}}$ & $(15,14,52,9,10)^{\mathrm{e}, \mathrm{f}}$ & $\%$ \\
Height L-box & $h_{\mathrm{L}}$ & 100 & $\mathrm{~m}$ \\
Height H-box & $h_{\mathrm{H}}^{\mathrm{g}}$ & 250 & $\mathrm{~m}$ \\
Height M-box & $h_{\mathrm{M}}$ & 900 & $\mathrm{~m}$ \\
Volume M-boxes $\mathrm{g}$ & $V_{i}$ & $0.817,0.565,1.445^{\mathrm{h}}$ & $10^{17} \mathrm{~m}^{3}$ \\
Volume M-boxes $\mathrm{g}$ & $V_{i}$ & $(0.471,0.440,1.633,0.283)^{\mathrm{j}}$ & $10^{17} \mathrm{~m}^{3}$ \\
Volume D-boxes & $V_{i}$ & $2.853,2.099,4.739^{\mathrm{h}}$ & $10^{17} \mathrm{~m}^{3}$ \\
Volume D-boxes $^{\mathrm{g}}$ & $V_{i}$ & $(1.540,1.540,6.547,0.063)^{\mathrm{j}}$ & $10^{17} \mathrm{~m}^{3}$ \\
\hline
\end{tabular}

a Default: modern version, parentheses: P/E-version. ${ }^{\mathrm{b}} 1: \mathrm{CO}_{2} ; 2: \mathrm{CO}_{2}$ and ${ }^{13} \mathrm{CO}_{2}$. c Toggweiler (1999). d Atlantic, Indian, Pacific, High-latitude. e (Atlantic, Indian, Pacific, Tethys, High-latitude). ${ }^{\mathrm{f}}$ Bice and Marotzke (2002). ${ }^{\mathrm{g}} \mathrm{L}=$ Low-latitude surface,

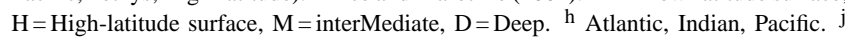
(Atlantic, Indian, Pacific, Tethys).

in the P/E-version. Box areas and volumes are given in Table 1 . The modern ocean geometry in LOSCAR is not unlike the one used by Walker and Kasting (1992). However, Walker and Kasting (1992) combined the warm surface and thermocline waters each into a single reservoir for a total of 6 boxes to represent the global modern ocean.

The modern and Paleocene/Eocene ocean bathymetry in LOSCAR is based on Menard and Smith (1966) and Bice and Marotzke (2002), respectively. The bathymetry determines the surface area and volume of ocean boxes (Table 1) and the surface area-depth level relationship of the sediment boxes (Sect. 6).

\subsection{Ocean tracer equations}

Let $y_{k}$ be a subset of $\boldsymbol{y}$ (Eq. 1), representing ocean tracer variables including $\mathrm{TCO}_{2}, \mathrm{TA}, \mathrm{PO}_{4}$, etc. (in this particular order). Then $k=1,2, \ldots, \mathrm{NB}$ for $\mathrm{TCO}_{2}, k=\mathrm{NB}+1, \mathrm{NB}+$ $2, \ldots, 2 \mathrm{NB}$ for TA, $k=2 \mathrm{NB}+1,2 \mathrm{NB}+2, \ldots, 3 \mathrm{NB}$ for $\mathrm{PO}_{4}$, and so on. If the total number of ocean tracers is NOCT, then the total number of equations for all ocean tracers and boxes is NOCT $\times$ NB. The differential equation for an ocean tracer $y_{k}$ may be written in the general form:

$V_{k} \frac{\mathrm{d} y_{k}}{\mathrm{~d} t}=F_{\text {thm }}+F_{\text {gas }}+F_{\text {bio }}+F_{\text {in }}+F_{\text {sed }}$,

where $V_{k}$ is the volume of box $k$ and $F$ 's are fluxes due to (thermohaline) circulation and mixing, air-sea gas exchange (e.g. in case of $\mathrm{TCO}_{2}$ ), biological uptake and remineralization, riverine/weathering input, and sediment fluxes. The first three flux terms on the right-hand side of Eq. (2) will be explained in the following subsections; the riverine/weathering and sediment flux terms will be explained in Sects. 4 and 6.

\subsubsection{Circulation, mixing, and air-sea gas exchange}

Given a prescribed ocean circulation- and mixing scheme, $F_{\text {thm }}$ is of the form:

$V_{k}\left(\frac{\mathrm{d} y_{k}}{\mathrm{~d} t}\right)_{\mathrm{thm}}=T \sum_{j}\left(y_{j}-y_{k}\right)+\sum_{l} m_{l k}\left(y_{l}-y_{k}\right)$

where $T$ is the volume transport of the conveyor circulation and $m_{l k}$ are mixing coefficients between boxes $l$ and $k$ (Fig. 2, Table 2). The box indices $j$ and $l$ are set by the prescribed circulation/mixing scheme (Fig. 2). The coefficients $m_{l k}$ represent bidirectional mixing, hence $m_{l k}=m_{k l}$.

The air-sea gas exchange term reads:

$V_{k}\left(\frac{\mathrm{d} y_{k}}{\mathrm{~d} t}\right)_{\mathrm{gas}}=\kappa_{\mathrm{as}} A_{k}\left(p \mathrm{CO}_{2}{ }^{\mathrm{a}}-\mathrm{PCO}_{2}{ }^{k}\right)$

where $\kappa_{\mathrm{as}}$ is the air-sea gas exchange coefficient for $\mathrm{CO}_{2}$ and $A_{k}$ is the area of surface box $k ; p \mathrm{CO}_{2}{ }^{\mathrm{a}}$ and $\mathrm{PCO}_{2}{ }^{k}$ is the atmospheric $p \mathrm{CO}_{2}$ and the $p \mathrm{CO}_{2}$ in equilibrium with dissolved $\mathrm{CO}_{2}$ in surface box $k$, respectively. The index $k$ runs over all surface boxes for tracers such as $\mathrm{TCO}_{2}$.

To derive the corresponding expression for the ${ }^{13} \mathrm{CO}_{2}$ flux, it is useful to rewrite $\kappa_{\mathrm{as}}$ as $\kappa_{\mathrm{as}}=u \beta$, where $u$ is the gas transfer velocity and $\beta$ the solubility (e.g. Siegenthaler and Münnich, 1981; Wanninkhof, 1985). Hence the air-sea $\mathrm{CO}_{2}$ flux per unit area may be written as:

$F_{\text {gas }}=u\left(\beta \cdot p \mathrm{CO}_{2}{ }^{\mathrm{a}}-\left[\mathrm{CO}_{2}\right]\right)$

where $\left[\mathrm{CO}_{2}\right]$ is the concentration of dissolved $\mathrm{CO}_{2}$ in solution. A similar equation holds for ${ }^{13} \mathrm{C}$ :

${ }^{13} F_{\text {gas }}={ }^{13} u\left({ }^{13} \beta \cdot p p^{13} \mathrm{CO}_{2}{ }^{\mathrm{a}}-\left[{ }^{13} \mathrm{CO}_{2}\right]\right)$.

Using $\alpha_{u}={ }^{13} u / u$ and $\alpha_{\mathrm{dg}}={ }^{13} \beta / \beta$, where $\alpha_{u}$ represents the kinetic fractionation during gas exchange and $\alpha_{\mathrm{dg}}$ the equilibrium fractionation between dissolved and gaseous $\mathrm{CO}_{2}$ (Mook, 1986; Zhang et al., 1995), it follows:

${ }^{13} F_{\text {gas }}=\kappa_{\text {as }} \alpha_{u}\left(\alpha_{\mathrm{dg}} \cdot p^{13} \mathrm{CO}_{2}{ }^{\mathrm{a}}-R_{\mathrm{d}} \beta^{-1}\left[\mathrm{CO}_{2}\right]\right)$,

where $\kappa_{\mathrm{as}}=u \beta$ (see above) and $R_{\mathrm{d}}$ is the ${ }^{12} \mathrm{C} /{ }^{13} \mathrm{C}$ ratio of dissolved $\mathrm{CO}_{2}$. $R_{\mathrm{d}}$ may be calculated taking into account the speciation and isotope fractionation among the various carbonate species (e.g. Wanninkhof, 1985; Zeebe and WolfGladrow, 2001). Alternatively, a simplified expression for $R_{\mathrm{d}}$ may be obtained assuming that the carbon isotope ratio of $\mathrm{HCO}_{3}^{-}\left(R_{\mathrm{b}}\right)$ is approximately equal to that of $\operatorname{TCO}_{2}\left(R_{\mathrm{b}} \simeq\right.$ $\left.R_{\mathrm{T}}\right)$. In other words, $R_{\mathrm{d}} \simeq \alpha_{\mathrm{db}} R_{\mathrm{T}}$, where $\alpha_{\mathrm{db}}$ is the fractionation between dissolved $\mathrm{CO}_{2}$ and $\mathrm{HCO}_{3}^{-}$(Mook, 1986; Zhang et al., 1995). Over the $\mathrm{pH}$ range from 7.5 to 8.2 and at $20^{\circ} \mathrm{C}$, this approximation differs from the full calculation by 0.2 to 
Table 2. Physical and biogeochemical parameters (ocean model).

\begin{tabular}{|c|c|c|c|c|}
\hline Parameter & Symbol & Modern & P/E-setup ${ }^{\mathrm{a}}$ & Unit \\
\hline Conveyor Transport & $T$ & $20^{\mathrm{b}}$ & 25 & $\mathrm{~Sv}^{\mathrm{c}}$ \\
\hline Tethys Transport & $T_{\mathrm{T}}$ & - & 2 & Sv \\
\hline Upwelling $(\mathrm{D}-\mathrm{M})^{\mathrm{d}}$ & $t_{\mathrm{A}}, t_{I}$ & $0.2,0.2^{\mathrm{e}, \mathrm{f}}$ & & - \\
\hline Mixing $(\mathrm{L}-\mathrm{M})^{\mathrm{d}}$ & $m_{l k}$ & $21,17,25^{\mathrm{g}, \mathrm{f}}$ & $13,13,27^{\mathrm{g}, \mathrm{f}}$ & Sv \\
\hline Mixing $(H-D)^{d}$ & $m_{l k}$ & $4,3,10^{\mathrm{g}, \mathrm{f}}$ & $5,5,8^{\mathrm{g}, \mathrm{f}}$ & $\mathrm{Sv}$ \\
\hline Mixing Tethys & $m_{l k}$ & - & $12,1,8^{\mathrm{h}, \mathrm{f}}$ & $\mathrm{Sv}$ \\
\hline Temperature (initial) & $T_{\mathrm{C}}^{0}$ & $20,10,2,2^{\mathrm{i}}$ & $25,16,12,12^{\mathrm{i}}$ & ${ }^{\circ} \mathrm{C}$ \\
\hline Temp. relax. time & $\tau_{n}$ & $20,200,1000^{j}$ & & $\mathrm{yr}$ \\
\hline Salinity & $S$ & 34.7 & & - \\
\hline Gas exch. coeff. $\mathrm{CO}_{2}$ & $\kappa_{\mathrm{as}}$ & $0.06^{\mathrm{k}}$ & & $\operatorname{mol}\left(\mu \mathrm{atm} \mathrm{m} \mathrm{yr}^{2}\right)^{-1}$ \\
\hline Biopump-efficiency & $f_{\mathrm{epl}}$ & $0.80^{\mathrm{f}}$ & & - \\
\hline Remin. fraction $(\mathrm{M})^{\mathrm{d}}$ & $f_{\text {rim }}$ & $0.78^{f}$ & & - \\
\hline Remin. fraction (D) ${ }^{d}$ & $1-f_{\text {rim }}$ & 0.22 & & - \\
\hline $\mathrm{P} / \mathrm{C}$ in $\mathrm{C}_{\text {org }}$ & REDPC & $1 / 130$ & & - \\
\hline $\mathrm{N} / \mathrm{C}$ in $\mathrm{C}_{\mathrm{org}}$ & REDNC & $15 / 130$ & & - \\
\hline $\mathrm{O}_{2} / \mathrm{C}\left(\mathrm{C}_{\text {org-remin. }}\right)$ & REDO2C & $165 / 130$ & & - \\
\hline C-export $(\mathrm{H})^{\mathrm{d}}$ & $F_{\text {eph }}$ & $1.8^{\mathrm{f}}$ & & $\mathrm{mol} \mathrm{m}^{-2} \mathrm{yr}^{-1}$ \\
\hline P-export $(\mathrm{H})^{\mathrm{d}}$ & $F_{\mathrm{pph}}$ & $F_{\mathrm{eph}} \times \mathrm{REDPC}$ & & $\mathrm{mol} \mathrm{m}^{-2} \mathrm{yr}^{-1}$ \\
\hline Rain ratio ${ }^{1}$ & $r_{\text {rain }}$ & 6.1 & $6.7^{\mathrm{f}}$ & - \\
\hline $\mathrm{CaCO}_{3}$ water dissol. $^{\mathrm{m}}$ & $v_{\mathrm{wc}}$ & $0.31^{\mathrm{f}}$ & & - \\
\hline
\end{tabular}

${ }^{a}$ Same as modern version unless indicated. ${ }^{b}$ Toggweiler (1999). ${ }^{\mathrm{c}} 1 \mathrm{~Sv}=10^{6} \mathrm{~m}^{3} \mathrm{~s}^{-1} .^{\mathrm{d}} \mathrm{L}=$ Low-latitude surface, $\mathrm{H}=\mathrm{High}-\mathrm{latitude}$ surface, $\mathrm{M}=\mathrm{InterMediate}$, D $=$ Deep. ${ }^{\mathrm{e}}$ Fraction upwelled into intermediate Atlantic, Indian (see Fig. 2). ${ }^{\mathrm{f}}$ Tuned. ${ }^{\mathrm{g}}$ Atlantic, Indian, Pacific. ${ }^{\mathrm{h}}$ (L-M Tethys, L-D Tethys, I-Tethys-I-Indian). ${ }^{\mathrm{i}}$ L, M, D, H-box. j Surface, intermediate, deep. ${ }^{\mathrm{k}}$ Broecker and Peng (1998). ${ }^{1} \mathrm{C}_{\mathrm{org}}: \mathrm{CaCO}_{3} \cdot{ }^{\mathrm{m}}$ Fraction of total $\mathrm{CaCO}_{3}$ export dissolved in water column.

$0.3 \%$. The simplified expression will thus suffice for most LOSCAR applications. Noting that $\beta^{-1} \cdot\left[\mathrm{CO}_{2}\right]=P \mathrm{CO}_{2}$, the air-sea gas-exchange term for ${ }^{13} \mathrm{CO}_{2}$ can then be written as:

$V_{k}\left(\frac{\mathrm{d} y_{k}}{\mathrm{~d} t}\right)_{\text {gas }}=\kappa_{\mathrm{as}} A_{k} \alpha_{u}\left(\alpha_{\mathrm{dg}}{ }^{k} \cdot p^{13} \mathrm{CO}_{2}{ }^{\mathrm{a}}-\alpha_{\mathrm{db}}{ }^{k} R_{\mathrm{T}}^{k} \cdot P \mathrm{CO}_{2}{ }^{k}\right)$.

This expression is readily evaluated in LOSCAR, which carries $p^{13} \mathrm{CO}_{2}{ }^{\mathrm{a}}, \mathrm{PCO}_{2}$, and $\mathrm{T}^{13} \mathrm{CO}_{2}$ as tracers (note that $\left.R_{\mathrm{T}}^{k}=\mathrm{T}^{13} \mathrm{CO}_{2}{ }^{k} / \mathrm{TCO}_{2}{ }^{k}\right)$. Values for the fractionation factors $(\alpha$ 's) as functions of temperature have been summarized in the literature (Mook, 1986; Zhang et al., 1995; Zeebe and Wolf-Gladrow, 2001). The user can choose between the sets of fractionation factors given by Mook (1986) and Zhang et al. (1995). However, the differences between the two sets are minor, except for the fractionation between $\mathrm{CO}_{3}^{2-}$ and $\mathrm{HCO}_{3}^{-}$, which is not used in LOSCAR given the simplified expressions above.

\subsubsection{Biological pump}

The biological uptake and recycling of tracers is parameterized based on phosphate ( $\mathrm{PO}_{4}$ for short). For instance, net uptake of $\mathrm{PO}_{4}$ in the low-latitude surface ocean (equivalent to particle export flux from the mixed layer) is calculated as:
$V_{k}\left(\frac{\mathrm{d}\left[\mathrm{PO}_{4}\right]_{k}}{\mathrm{~d} t}\right)_{\mathrm{upt}}=F_{\mathrm{ppl}}^{k}=-f_{\mathrm{epl}} m_{j k}\left[\mathrm{PO}_{4}\right]_{j}$,

where the parameter $f_{\text {epl }}$ describes the efficiency for $\mathrm{PO}_{4}$ uptake in the low-latitude surface boxes, $m_{j k} \times\left[\mathrm{PO}_{4}\right]_{j}$ is the flux of $\mathrm{PO}_{4}$ supplied by upwelling/mixing from the underlying intermediate box $j$ into the surface box $k$. (Note that in the model, the conveyor transport $T$ does not directly supply nutrients to the warm surface waters; it does so, however, to the cold surface waters, see Fig. 2). If $f_{\text {epl }}$ were to approach 1.0 (100\% efficiency), all upwelled $\mathrm{PO}_{4}$ would be converted to sinking particles and the phosphate concentration of surface box $k$ would be zero. In the model, as well as in reality, $f_{\text {epl }}$ is usually less than 1.0 (Table 2 ). The fraction $f_{\text {rim }}$ of the export flux is remineralized in the intermediate box, whereas the fraction $\left(1-f_{\text {rim }}\right)$ is remineralized in the deep box.

The high-latitude $\mathrm{PO}_{4}$ export flux can be set directly by assigning a value to the flux parameter $F_{\mathrm{pph}}$. If the value chosen is too large to be supported by the total $\mathrm{PO}_{4}$ influx entering the H-box, simple Michaelis-Menten kinetics prevent $\mathrm{PO}_{4}$ from becoming negative. Caution is therefore advised when increasing $F_{\text {pph }}$ because the actual high-latitude export flux may be less than the value assigned to $F_{\mathrm{pph}}$. The high-latitude export flux is remineralized in the deep boxes.

The fluxes of $\mathrm{TCO}_{2}$ and TA due to biological uptake and recycling are computed based on $\mathrm{PO}_{4}$ using a given Redfield- 

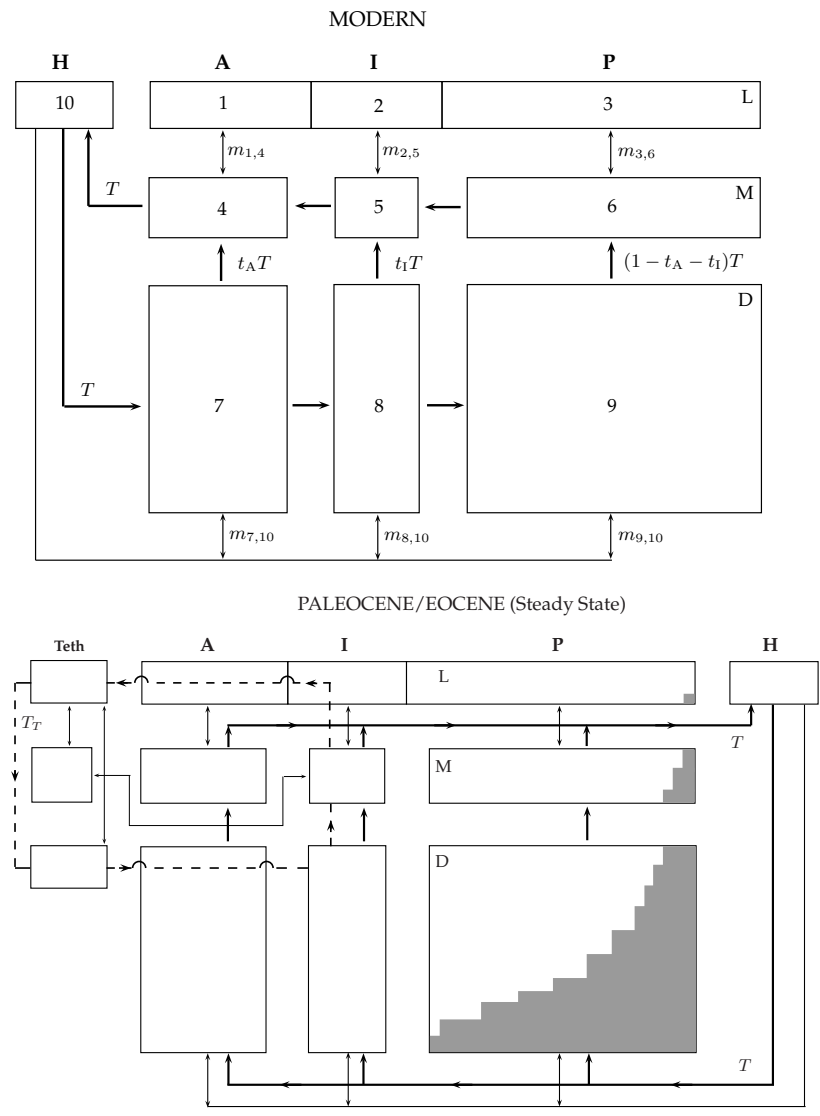

Fig. 2. Ocean circulation and mixing schemes implemented in LOSCAR for modern setup (top) and Paleocene/Eocene (P/E) steady-state (bottom). A = Atlantic, $\mathrm{I}=$ Indian, $\mathrm{P}=$ Pacific ocean, $\mathrm{H}=$ High-latitude surface, Teth $=$ Tethys. $\mathrm{L}=$ Low-latitude surface, $\mathrm{M}=$ interMediate, $\mathrm{D}=$ Deep box. $T$ represents the conveyor transport, while the coefficients $m_{l k}$ represent bidirectional mixing between boxes. The generic H-box represents cold surface waters without reference to a specific location. Nevertheless, the modern setup is motivated by preindustrial circulation patterns with significant deep water formation in the North Atlantic (e.g. Walker and Kasting, 1992; Toggweiler, 1999). The P/E steady-state setup is inspired by observations and modeling studies of Paleocene/Eocene circulation patterns with significant deep water formation in the Southern Ocean (e.g. Bice and Marotzke, 2002; Thomas et al., 2003; Lunt et al., 2010). $T_{\mathrm{T}}$ (dashed line) represents the Tethys circulation, which connects to the Indian Ocean (note that the $T_{\mathrm{T}^{-}}$ surface and deep branch do not flow through Atlantic boxes, as indicated by arcs). Note also that a transient contribution of North Pacific Deep Water (not shown) was included in our PETM simulations (Zeebe et al., 2009). All ocean boxes (except H-box) in the modern and P/E-setup are coupled to sediment boxes (schematically indicated only in the bottom panel for the Pacific by the gray shaded area).

and rain ratio (Table 2). Note that there is a small contribution to alkalinity changes from organic carbon production and respiration as a result of nitrate uptake and release (e.g. Zeebe and Wolf-Gladrow, 2001). The major contribution to alkalinity changes in the model is associated with $\mathrm{CaCO}_{3}$ fluxes. Of the total $\mathrm{CaCO}_{3}$ export flux, the larger fraction is destined for accumulation or dissolution in sediments, the latter of which returns total carbon and alkalinity to the ocean (Sect. 6). A smaller fraction of the $\mathrm{CaCO}_{3}$ export is assumed to dissolve in the water column (Table 2). This assumption yields better agreement with observed TA fields and is consistent with observations and modeling studies indicating substantial water column dissolution above the lysocline (e.g. Archer et al., 1998; Milliman et al., 1999; Feely et al., 2002). In the model, the fraction representing $\mathrm{CaCO}_{3}$ water column dissolution is added to the corresponding deep boxes, hence increasing $\mathrm{TCO}_{2}$ and $\mathrm{TA}$ in these boxes.

The export flux of $\mathrm{T}^{13} \mathrm{CO}_{2}$ is determined based on the total carbon export flux and a carbon isotope fractionation factor representing the isotope effect associated with the fixation of organic matter. For example, in the low-latitude surface, the $\mathrm{T}^{13} \mathrm{CO}_{2}$ flux is computed as:

${ }^{13} F_{\mathrm{epl}}^{k}=\alpha_{(\mathrm{Corg}-T)} R_{\mathrm{T}}^{k} F_{\mathrm{epl}}^{k}$

where $F_{\text {epl }}^{k}$ is the total carbon export flux from box $k$, $R_{\mathrm{T}}^{k}=\mathrm{T}^{13} \mathrm{CO}_{2}{ }^{k} / \mathrm{TCO}_{2}{ }^{k}$, and $\alpha_{(\mathrm{Corg}-T)}=0.9723$ represents the carbon isotope fractionation between organic carbon and $\mathrm{TCO}_{2}$. The fractionation factor $\alpha_{(\mathrm{Corg}-T)}$, or more precisely its corresponding $\varepsilon$-value $\left[\varepsilon=(\alpha-1) 10^{3}\right]$, should not be confused with the isotopic difference between the carbon source and fixed carbon, often denoted as $\varepsilon_{\mathrm{p}}$ (e.g. Hayes, 1993). While $\varepsilon_{\mathrm{p}}$ requires knowledge about the photosynthetic carbon source (e.g. $\mathrm{CO}_{2}$ or $\left.\mathrm{HCO}_{3}^{-}\right), \varepsilon_{(\mathrm{Corg}-T)}$ does not. $\varepsilon_{(\mathrm{Corg}-T)}$ is a model-specific, tunable parameter representing a globally averaged value for the marine carbon isotope fractionation between organic carbon and $\mathrm{TCO}_{2}$. It is tuned so as to reproduce the observed $\delta^{13} \mathrm{C}$ distribution in the ocean. For the sake of simplicity, no fractionation is associated with the precipitation and dissolution of $\mathrm{CaCO}_{3}$ in the model.

\section{Carbonate and silicate weathering}

Weathering of carbonate rocks on the continents takes up atmospheric $\mathrm{CO}_{2}$ and supplies calcium and bicarbonate ions to the ocean:

$\mathrm{CaCO}_{3}+\mathrm{H}_{2} \mathrm{O}+\mathrm{CO}_{2} \rightleftharpoons \mathrm{Ca}^{2+}+2 \mathrm{HCO}_{3}^{-}$.

Hence two moles of carbon and one mole of $\mathrm{Ca}^{2+}$ enter the ocean for each mole of $\mathrm{CaCO}_{3}$ weathered, raising ocean $\mathrm{TCO}_{2}$ and TA by two units each (Fig. 3). If the $\mathrm{CaCO}_{3}$ riverine/weathering influx is denoted by $F_{\mathrm{cc}}$ (in units of $\mathrm{mol} \mathrm{CaCO}_{3} \mathrm{yr}^{-1}$, see Table 3), then:

$V_{k}\left(\frac{\mathrm{d}\left[\mathrm{TCO}_{2}\right]_{k}}{\mathrm{~d} t}\right)_{\mathrm{cc}}=V_{k}\left(\frac{\mathrm{d}[\mathrm{TA}]_{k}}{\mathrm{~d} t}\right)_{\mathrm{cc}}=2 F_{\mathrm{cc}} \mathrm{NOC}^{-1}$

where $k=1, \ldots$, NOC runs over all low-latitude surface boxes and NOC is the number of corresponding ocean basins. Note 
Table 3. Weathering and sediment model parameters.

\begin{tabular}{|c|c|c|c|}
\hline Parameter & Symbol & Value $^{\mathrm{a}}$ & Unit \\
\hline $\mathrm{CaCO}_{3}$ weath. flux (initial) & $F_{\mathrm{cc}}^{0}$ & $12^{\mathrm{b}}(16)$ & $10^{12} \mathrm{~mol} \mathrm{yr}^{-1}$ \\
\hline $\mathrm{CaSiO}_{3}$ weath. flux (initial) & $F_{\mathrm{si}}^{0}$ & $5^{\mathrm{c}}(6)$ & $10^{12} \mathrm{~mol} \mathrm{yr}^{-1}$ \\
\hline $\mathrm{CO}_{2}$ degass. flux (initial) & $F_{\mathrm{vc}}^{0}$ & $F_{\mathrm{si}}^{0}$ & $10^{12} \mathrm{~mol} \mathrm{yr}^{-1}$ \\
\hline $\mathrm{CaCO}_{3}$ weath. exponent & $n_{\mathrm{cc}}$ & $0.4^{\mathrm{d}}$ & - \\
\hline $\mathrm{CaSiO}_{3}$ weath. exponent & $n_{\mathrm{si}}$ & $0.2^{\mathrm{d}}$ & - \\
\hline$\delta^{13} \mathrm{C}$ weath. & $\delta^{13} \mathrm{C}_{\mathrm{in}}$ & $1.5(2.0)$ & $\%$ \\
\hline$\delta^{13} \mathrm{C}$ degass. & $\delta^{13} \mathrm{C}_{\mathrm{vc}}$ & -4 & $\%$ \\
\hline Height sediment mixed layer & $h_{\mathrm{S}}$ & 0.08 & $\mathrm{~m}$ \\
\hline Density, solids & $\rho_{\mathrm{S}}$ & $2.5 \times 10^{3}$ & $\mathrm{~kg} \mathrm{~m}^{-3}$ \\
\hline non- $\mathrm{CaCO}_{3}$ flux ${ }^{\mathrm{e}}$ & $F_{\text {rrf }}$ & $0.35 \times 10^{-2}$ & $\mathrm{~kg} \mathrm{~m}^{-2} \mathrm{yr}^{-1}$ \\
\hline Porosity, pure clay & $\phi_{0}$ & $0.85^{\mathrm{f}}$ & - \\
\hline Porosity, pure $\mathrm{CaCO}_{3}$ & $\phi_{1}$ & $0.62^{\mathrm{f}}$ & - \\
\hline Dissolution rate const. (eff.) ${ }^{\mathrm{g}}$ & $K_{\mathrm{sd}}$ & $20.36 \times 10^{10}$ & $\mathrm{~mol} \mathrm{~m}^{-2} \mathrm{yr}^{-1}$ \\
\hline Dissolution rate order (eff. $)^{\mathrm{g}}$ & $n_{\mathrm{sd}}$ & 2.40 & - \\
\hline
\end{tabular}

${ }^{a}$ Default: modern version, parentheses: P/E-version. ${ }^{b}$ Morse and Mackenzie (1990). ${ }^{\mathrm{c}}$ Walker and Kasting (1992). ${ }^{\mathrm{d}}$ Uchikawa and Zeebe (2008). ${ }^{\mathrm{e}} \mathrm{Rain}$ of refractory, non-CaCO 3 material to sediments. ${ }^{\mathrm{f}}$ See Zeebe and Zachos (2007). ${ }^{\mathrm{g}}$ Effective rate parameters, relating bottom water undersaturation to dissolution rate (Keir, 1982; Sundquist, 1986; Sigman et al., 1998; Zeebe and Zachos, 2007); $n_{\text {sd }}$ is not to be confused with the calcite reaction order $n$, relating porewater undersaturation to dissolution rate (typically $n=4.5$ ).

that in steady state, subsequent precipitation of $\mathrm{CaCO}_{3}$ in the ocean (Reaction 11 backwards) releases the same amount of $\mathrm{CO}_{2}$ back into the atmosphere as was taken up during weathering. In other words, the $\mathrm{CO}_{2}$ for carbonate weathering essentially originates from the ocean (Fig. 3). As a result, although the addition of $\mathrm{Ca}^{2+}$ and $2 \mathrm{HCO}_{3}^{-}$increases ocean $\mathrm{TCO}_{2}$ : TA in a 2:2 ratio, on a net basis $\mathrm{CaCO}_{3}$ weathering increases ocean $\mathrm{TCO}_{2}$ : TA in a $1: 2$ ratio because one mole of $\mathrm{CO}_{2}$ returns to the atmosphere. If influx equals burial, carbonate weathering thus represents a zero net balance for atmospheric $\mathrm{CO}_{2}$. The steady-state balance is restored after a perturbation on a time scale of 5 to $10 \mathrm{kyr}$ and is referred to as "calcite compensation" (Broecker and Peng, 1987; Zeebe and Westbroek, 2003).

Weathering of silicate rocks and simultaneous uptake of atmospheric $\mathrm{CO}_{2}$ may be described by:

$\mathrm{CaSiO}_{3}+\mathrm{H}_{2} \mathrm{O}+2 \mathrm{CO}_{2} \rightleftharpoons \mathrm{Ca}^{2+}+2 \mathrm{HCO}_{3}^{-}+\mathrm{SiO}_{2}$.

If the $\mathrm{CaSiO}_{3}$ riverine/weathering influx is denoted by $F_{\text {si }}$ (in units of mol $\mathrm{CaSiO}_{3} \mathrm{yr}^{-1}$, see Table 3), then:

$V_{k}\left(\frac{\mathrm{d}\left[\mathrm{TCO}_{2}\right]_{k}}{\mathrm{~d} t}\right)_{\mathrm{si}}=V_{k}\left(\frac{\mathrm{d}[\mathrm{TA}]_{k}}{\mathrm{~d} t}\right)_{\mathrm{si}}=2 F_{\mathrm{si}} \mathrm{NOC}^{-1}$.

Note that silicate weathering removes 2 moles of $\mathrm{CO}_{2}$ from the atmosphere for each mole of $\mathrm{CaSiO}_{3}$ weathered. Subsequent precipitation and burial of $\mathrm{CaCO}_{3}$ (Reaction 11 backwards) releases one mole of $\mathrm{CO}_{2}$ back to the atmosphere, the other mole is buried in the form of $\mathrm{CaCO}_{3}$ in sediments (Fig. 3). In steady state, the balance is closed by longterm $\mathrm{CO}_{2}$ input to the atmosphere from volcanic degassing. Putting it the other way, the $\mathrm{CO}_{2}$ released by volcanoes is balanced by silicate weathering and subsequent carbonate burial in the ocean (Fig. 3). The net reaction is:

$$
\mathrm{CaSiO}_{3}+\mathrm{CO}_{2} \rightleftharpoons \mathrm{CaCO}_{3}+\mathrm{SiO}_{2} \text {. }
$$

The steady-state balance for silicate weathering is restored after a perturbation on a time scale of $10^{5}$ to $10^{6} \mathrm{yr}$. This process also restores the partial pressure of atmospheric $\mathrm{CO}_{2}$ in order to maintain a mass balance of long-term carbon cycle fluxes (e.g. Berner et al., 1983; Zeebe and Caldeira, 2008).

The restoring time scale for silicate weathering is much longer than for carbonate weathering for two reasons. First, silicate weathering requires whole-ocean $\mathrm{TCO}_{2}$ to adjust, whereas carbonate weathering only requires the ocean's carbonate ion concentration to adjust (e.g. Zeebe and Westbroek, 2003). On average, the modern $\mathrm{TCO}_{2}$ inventory is about 20 times larger than mean-ocean $\left[\mathrm{CO}_{3}^{2-}\right]$ (e.g. Broecker and Peng, 1998). Second, carbonate weathering fluxes have been estimated to be about 2.5-times larger than silicate weathering fluxes (Table 3; Morse and Mackenzie, 1990; Walker and Kasting, 1992). Combined, this gives a factor of about 50, which, multiplied by the calcite compensation time scale of $10 \mathrm{kyr}$, gives $500 \mathrm{kyr}$, which is about right.

\subsection{Weathering feedback}

The feedback between atmospheric $\mathrm{CO}_{2}$ and weathering fluxes of carbonates and silicates is parameterized in the model using the following equations (see Walker et al., 1981; Berner et al., 1983; Walker and Kasting, 1992):

$$
\begin{aligned}
F_{\mathrm{cc}} & =F_{\mathrm{cc}}^{0}\left(p \mathrm{CO}_{2} / p \mathrm{CO}_{2}^{0}\right)^{n_{\mathrm{cc}}} \\
F_{\mathrm{si}} & =F_{\mathrm{si}}^{0}\left(p \mathrm{CO}_{2} / p \mathrm{CO}_{2}^{0}\right)^{n_{\mathrm{si}}}
\end{aligned}
$$


Carbonate Weathering

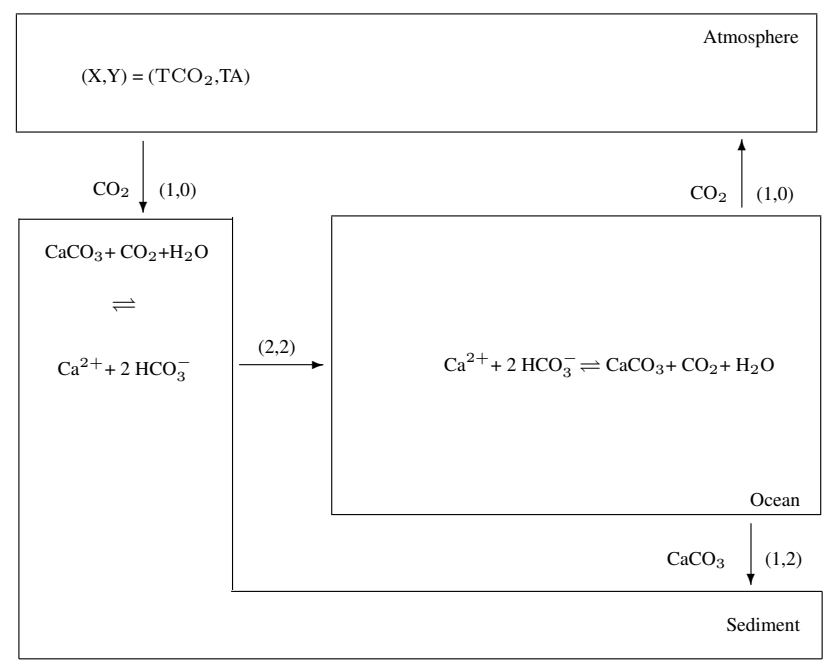

Silicate Weathering

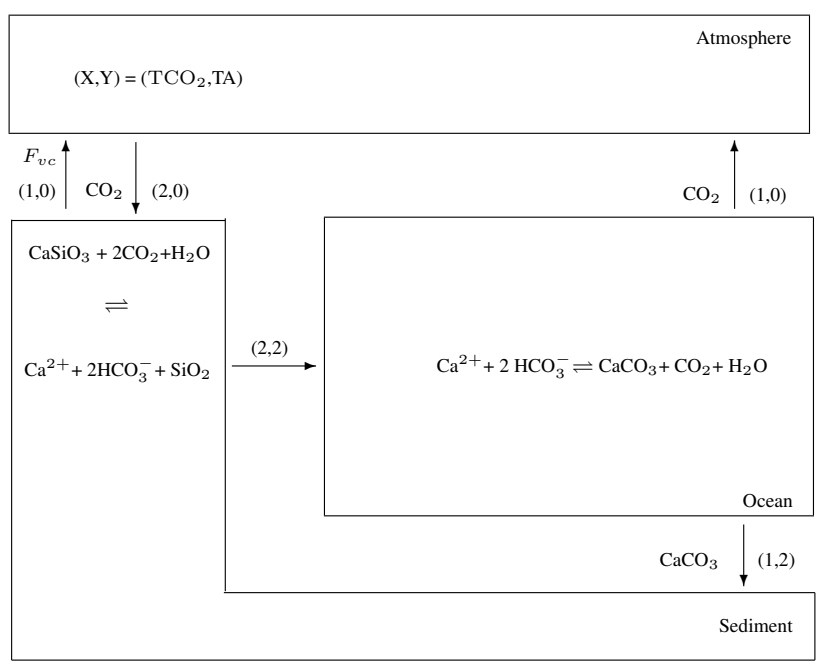

Fig. 3. Schematic illustration of carbonate and silicate weathering fluxes. Numbers in parentheses indicate steady-state fluxes of $\mathrm{TCO}_{2}$ and TA in mole per mole of $\mathrm{CaCO}_{3}$ or $\mathrm{CaSiO}_{3}$ weathered.

where the superscript " 0 " refers to the initial (steady-state) value of the weathering flux and $p \mathrm{CO}_{2}$, respectively. The parameters $n_{\mathrm{cc}}$ and $n_{\mathrm{si}}$ control the strength of the weathering feedback (Table 3). The default values for $n_{\mathrm{cc}}$ and $n_{\mathrm{si}}$ adopted in LOSCAR were chosen so as to represent conservative values, resulting in a weak default weathering feedback at the lower end of the spectrum (see Fig. 1 in Uchikawa and Zeebe, 2008). The user is welcome to change and vary these parameters values (cf. Uchikawa and Zeebe, 2008; Komar and Zeebe, 2011).

As mentioned above, in steady state, the silicate weathering flux balances the $\mathrm{CO}_{2}$ degassing flux from volcanism:

$F_{\mathrm{si}}^{0}=F_{\mathrm{vc}}^{0}$.
Thus, the long-term steady-state $p \mathrm{CO}_{2}$ of the model is set by picking a value for $p \mathrm{CO}_{2}^{0}$, which drives the system towards equilibrium via the silicate weathering equation (Eq. 17). Only when the actual model $p \mathrm{CO}_{2}$ equals $p \mathrm{CO}_{2}^{0}$, will the fluxes be balanced $\left(F_{\mathrm{si}}=F_{\mathrm{si}}^{0}=F_{\mathrm{vc}}^{0}\right)$. The carbon isotope composition of the volcanic degassing flux is set to $-4.0 \%$ o in the model, while the $\delta^{13} \mathrm{C}$ of the weathering flux is set to $1.5 \%$ and $2.0 \%$ for the modern and P/E-setup, respectively (see Table 3).

\section{Atmosphere}

The model variable tracking the inventory of atmospheric carbon dioxide, $\mathrm{C}_{\mathrm{atm}}$, is related to the partial pressure of $\mathrm{CO}_{2}$ in the atmosphere by (analogous for ${ }^{13} \mathrm{C}$ ):

$$
\begin{aligned}
\mathrm{C}_{\mathrm{atm}} & =p \mathrm{CO}_{2}{ }^{\mathrm{a}} \times q^{0} \\
{ }^{13} \mathrm{C}_{\mathrm{atm}} & =p^{13} \mathrm{CO}_{2}{ }^{\mathrm{a}} \times q^{0}
\end{aligned}
$$

where $q^{0}=\left(2.2 \times 10^{15} / 12\right) \mathrm{mol} \mu \mathrm{atm}^{-1}$ converts from $\mu$ atm to mol. Note that for numerical scaling purposes (see Sect. 7.4), $\mathrm{C}_{\mathrm{atm}}$ is normalized to order 1 in the program by multiplying by $\left(A_{\mathrm{oc}} \times 100\right)^{-1}$ (arbitrary factor). The differential equations for $\mathrm{C}_{\mathrm{atm}}$ and ${ }^{13} \mathrm{C}_{\mathrm{atm}}$ may be written in the general form:

$$
\begin{aligned}
\frac{\mathrm{d} \mathrm{C} \text { atm }}{\mathrm{d} t} & =F_{\text {gas }}+F_{\mathrm{vc}}-F_{\mathrm{cc}}-2 F_{\mathrm{si}}+C_{\mathrm{in}}^{\prime} \\
\frac{\mathrm{d}{ }^{13} \mathrm{C}_{\mathrm{atm}}}{\mathrm{d} t} & ={ }^{13} F_{\mathrm{gas}}+{ }^{13} F_{\mathrm{vc}}-{ }^{13} F_{\mathrm{cc}}-2{ }^{13} F_{\mathrm{si}}+{ }^{13} C_{\mathrm{in}}^{\prime},
\end{aligned}
$$

where $F$ 's are fluxes due to air-sea gas exchange, volcanic input and weathering (see Sect. 4), and possible carbon input sources. Fluxes of ${ }^{13} \mathrm{C}$ due to volcanic degassing and weathering are calculated from ${ }^{13} F_{j}=R_{j} F_{j}$, where $R_{j}=R_{\text {std }}\left(\delta^{13} \mathrm{C}_{j} / 1 \times 10^{3}+1\right)$ and $\delta^{13} \mathrm{C}_{j}$ is set to $-4.0 \%$ and $1.5 \%$, respectively, for the modern version (see Table 3 ).

The air-sea gas exchange terms for the atmosphere read:

$$
\left(\frac{\mathrm{d} \mathrm{C} \text { atm }}{\mathrm{d} t}\right)_{\mathrm{gas}}=\sum_{k} \kappa_{\mathrm{as}} A_{k}\left(P \mathrm{CO}_{2}{ }^{k}-p \mathrm{CO}_{2}{ }^{\mathrm{a}}\right)
$$

$$
\begin{aligned}
& \left(\frac{\mathrm{d}^{13} \mathrm{C}_{\mathrm{atm}}}{\mathrm{d} t}\right)_{\mathrm{gas}}= \\
& \sum_{k} \kappa_{\mathrm{as}} A_{k} \alpha_{u}\left(\alpha_{\mathrm{db}}{ }^{k} R_{\mathrm{T}}^{k} \cdot P \mathrm{CO}_{2}{ }^{k}-\alpha_{\mathrm{dg}}{ }^{k} \cdot p^{13} \mathrm{CO}_{2}{ }^{\mathrm{a}}\right)
\end{aligned}
$$

where $\kappa_{\mathrm{as}}$ is the air-sea gas exchange coefficient for $\mathrm{CO}_{2}$ and $A_{k}$ is the area of surface box $k ; p \mathrm{CO}_{2}{ }^{\mathrm{a}}$ and $\mathrm{PCO}_{2}{ }^{k}$ is the atmospheric $p \mathrm{CO}_{2}$ and the $p \mathrm{CO}_{2}$ in equilibrium with dissolved $\mathrm{CO}_{2}$ in surface box $k$, respectively. For details regarding the gas-exchange term for ${ }^{13} \mathrm{C}$, see Sect. 3.2.1. The sum runs over all surface boxes. In case of carbon input to 
(a) Net accumulation
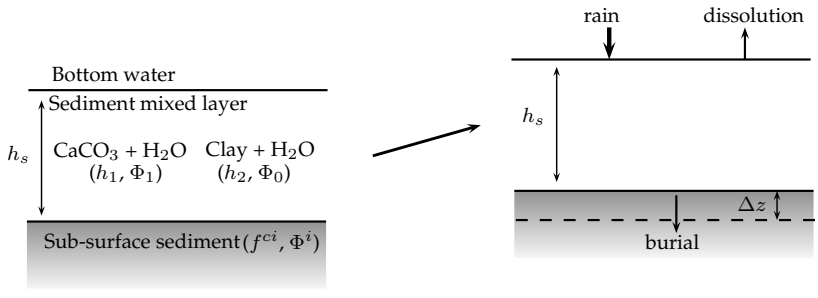

(b) Erosion
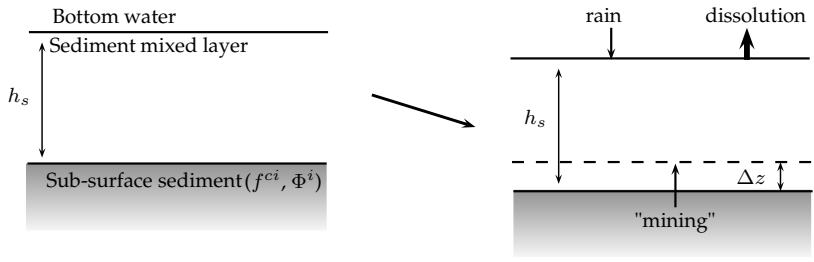

Fig. 4. Schematic representation of the sediment model. The sediment mixed layer (thickness $h_{\mathrm{s}}$ ) can be separated into pure calcite plus pore water (thickness $h_{1}$, porosity $\phi_{1}$ ) and pure clay plus pore water (thickness $h_{2}$, porosity $\phi_{0}$ ). (a) Net accumulation equals $\mathrm{CaCO}_{3}$ rain minus dissolution. At the bottom of the sediment mixed layer, an amount equal to net accumulation is removed via burial $(\Delta z)$. (b) If dissolution of $\mathrm{CaCO}_{3}$ exceeds the rain of $\mathrm{CaCO}_{3}$ plus clay, chemical erosion occurs. Previously deposited, underlying sediment is reintroduced into the top layer and exposed to dissolution ("mining"). Sub-surface sediment properties are based on the initial steady-state configuration $\left(f^{\mathrm{c} i}\right.$ and $\phi^{i}$ is the initial calcite fraction and porosity, respectively).

the atmosphere from fossil fuel burning or from other carbon sources, for instance, during the PETM, terms of the form:

$$
\begin{gathered}
\left(\frac{\mathrm{d} \mathrm{C}_{\mathrm{atm}}}{\mathrm{d} t}\right)_{C_{\mathrm{in}}}=C_{\mathrm{in}} \times 10^{15} / 12 \\
\left(\frac{\mathrm{d}^{13} \mathrm{C}_{\mathrm{atm}}}{\mathrm{d} t}\right)_{C_{\mathrm{in}}}={ }^{13} C_{\mathrm{in}} \times 10^{15} / 12
\end{gathered}
$$

are added where $C_{\text {in }}$ is in units of $\mathrm{Pg} \mathrm{Cyr}^{-1}$ and ${ }^{13} C_{\text {in }}=$ $R_{\text {in }} C_{\text {in }}$, where $R_{\text {in }}$ is the carbon isotope ratio of the carbon source.

\section{Sediments}

The sediment model calculates $\% \mathrm{CaCO}_{3}$ (dry weight) in the seafloor-bioturbated (mixed) sediment layer of thickness $h_{\mathrm{s}}$ as a function of sediment rain, dissolution, burial, and chemical erosion (for more details see Fig. 4 and Zeebe and Zachos, 2007). The model is particularly useful for long-term integrations and has been constructed similar to other models of this class (e.g. Keir, 1982; Sundquist, 1986; Sigman et al., 1998). However, the current model also includes variable porosity - a feature critical to simulating strong dissolution events that lead to sediment erosion, such as expected for the future or during the PETM (Zeebe and Zachos, 2007; Zeebe et al., 2008, 2009).

\subsection{Chemical erosion}

When dissolution of $\mathrm{CaCO}_{3}$ exceeds the rain of $\mathrm{CaCO}_{3}$ plus refractory material such as clay, the sediment column shrinks and previously deposited, underlying sediment is reintroduced into the top layer and exposed to dissolution. This is referred to as chemical erosion (Fig. 4). As a result, significantly more $\mathrm{CaCO}_{3}$ is available for dissolution during erosion than originally contained in the top sediment layer. Once the top layer is entirely filled with clay, the sediment column is "sealed" and dissolution ceases. In order to fill the sediment top layer with clay, the sediment volume that was initially filled with $\mathrm{CaCO}_{3}+$ pore water must be replaced by clay + pore water. Thus, if the sediment porosity $\phi$ is constant, the ratio of total $\mathrm{CaCO}_{3}$ available during erosion to the mass contained in the original surface layer is given by:

$1+\frac{f^{c i}}{\left(1-f^{c i}\right)}$

(Broecker and Takahashi, 1977) where $f^{\mathrm{ci}}$ and $\left(1-f^{\mathrm{ci}}\right)$ are the initial $\mathrm{CaCO}_{3}$ and clay dry weight fraction of the sediment, respectively. However, if porosity varies with $\% \mathrm{CaCO}_{3}$ (as observations show, see below), the ratio of total dissolved to initial $\mathrm{CaCO}_{3}$ is given by:

$1+\frac{1-\phi_{0}}{1-\phi_{1}} \frac{f^{\mathrm{c} i}}{1-f^{\mathrm{c} i}}$

where $\phi_{0}$ and $\phi_{1}$ are the porosities of a pure clay and calcite layer, respectively. The factor $\left(1-\phi_{0}\right) /\left(1-\phi_{1}\right)$ is of the order $0.3-0.5$ and therefore significant as it reduces the erodible $\mathrm{CaCO}_{3}$ from below the bioturbated layer by 50 $70 \%$ compared to the constant $\phi$ estimate (Archer, 1996). In LOSCAR, chemical erosion is included based on Eq. (37), see below.

\subsection{Variable porosity}

In many locations, it has been observed that porosity decreases with greater $\mathrm{CaCO}_{3}$ fraction $f^{\mathrm{c}}$ (e.g. Mayer, 1991; Herbert and Mayer, 1991; deMenocal et al., 1993). That is, sediment with high $\mathrm{CaCO}_{3}$ content has a higher concentration of total solids per unit volume than low carbonate sediment. The relationship between $\phi$ and $f^{\mathrm{c}}$ for a sediment layer composed of $\mathrm{CaCO}_{3}$, clay, and pore water is given by:

$\phi=\frac{\phi_{0}+f^{\mathrm{c}} F_{\phi}}{1+f^{\mathrm{c}} F_{\phi}}$

where $F_{\phi}=\left(\phi_{1}-\phi_{0}\right) /\left(1-\phi_{1}\right)$. The sediment model uses variable porosity as given by Eq. (29) and values for $\phi_{0}$ and $\phi_{1}$ as given in Table 3. Note that using the non-linear Eq. (29) in the model leads to the correct ratio of initial to erodible 
$\mathrm{CaCO}_{3}$ (cf. Eq. 28, which was independently derived based on the geometry of the problem), while a linear relationship, for instance, would not.

\subsection{Sediment model equations (single sediment box)}

At every time step, calcite and clay rain of solid density $\rho_{\mathrm{s}}$ is added to the top sediment layer of thickness $h_{\mathrm{S}}$ (see Table 3 for values). Dissolution of calcite reduces the calcite content and net accumulation is hence rain minus dissolution (Fig. 4). At the bottom of the sediment mixed layer, an amount equal to net accumulation is removed via burial. If dissolution of $\mathrm{CaCO}_{3}$ exceeds the rain of $\mathrm{CaCO}_{3}$ plus clay, chemical erosion occurs. The sediment model thus has to provide equations to calculate rain, dissolution, burial, and erosion. At variable porosity, the top layer can be separated into pure calcite plus pore water at porosity $\phi_{1}\left(\right.$ volume $\left.=A h_{1}\right)$ and pure clay plus pore water at porosity $\phi_{0}\left(\right.$ volume $\left.=A h_{2}\right)$. For variable porosity, the model equations can be conveniently written in terms of $\mathrm{d} h_{1} / \mathrm{d} t$. Conversion to $\mathrm{d} f^{\mathrm{c}} / \mathrm{d} t$ merely requires multiplication by a factor (see below).

In case rain exceeds dissolution, no erosion needs to be considered and we can write for a single sediment box:

$$
\frac{\mathrm{d} h_{1}}{\mathrm{~d} t}=r^{\mathrm{cs}}-r^{\mathrm{d}}-w^{\mathrm{c}}
$$

where $r^{\mathrm{cs}}$ is the calcite rain rate, $r^{\mathrm{d}}$ is the calcite dissolution rate, and $w^{\mathrm{c}}$ is the calcite burial rate. All rates refer to volume of calcite plus pore water per unit area and time (unit $\mathrm{m} \mathrm{yr}^{-1}$ ) at porosity $\phi_{1}$. Total rates of calcite + clay + pore water are denoted by $r^{\mathrm{s}}$ and $w$. Burial equals rain minus dissolution, i.e. $w=r^{\mathrm{s}}-r^{\mathrm{d}}$, and the condition for no erosion is $w>0$. The rain rate of calcite, $r^{\mathrm{cs}}$, depends on the carbon export, the rain ratio, and the fraction of water column dissolution. In the low latitudes, for instance, $r^{\mathrm{cs}}$ is given by:

$r^{\mathrm{cs}}=F_{\mathrm{epl}} r_{\text {rain }}{ }^{-1}\left(1-v_{\mathrm{wc}}\right) \times k^{*}$

where $F_{\text {epl }}$ is the low-latitude carbon export (in units of mol m$\left.{ }^{-2} \mathrm{yr}^{-1}\right), r_{\text {rain }}$ is the rain ratio $\left(\mathrm{C}_{\mathrm{org}}: \mathrm{CaCO}_{3}\right), v_{\mathrm{wc}}$ is the $\mathrm{CaCO}_{3}$ fraction dissolved in the water column (Table 2), $k^{*}=k^{0} /\left[\rho_{\mathrm{s}}\left(1-\phi_{1}\right)\right]$ converts from $\mathrm{mol} \mathrm{m}^{-2} \mathrm{yr}^{-1}$ to $\mathrm{m} \mathrm{yr}^{-1}$, and $k^{0}=\left(100 / 10^{3}\right) \mathrm{kg} \mathrm{mol}^{-1}$ converts from $\mathrm{mol} \mathrm{CaCO}_{3}$ to $\mathrm{kg} \mathrm{CaCO}_{3}$. The rain rate of refractory material, $r^{\mathrm{rs}}$, is calculated correspondingly based on $F_{\text {rrf }}$ (Table 3 ) and the total rain $r^{\mathrm{s}}$ is given by $r^{\mathrm{s}}=r^{\mathrm{cs}}+r^{\mathrm{rs}}$.

The dissolution rate, $r^{\mathrm{d}}$, is calculated as:

$r^{\mathrm{d}}=\mathcal{R}^{\mathrm{d}} \times k^{*}$,

where $\mathcal{R}^{\mathrm{d}}$ is given by the following expression at modern seawater $\mathrm{Mg} / \mathrm{Ca}$ ratio (Keir, 1982; Sigman et al., 1998):

$\mathcal{R}^{\mathrm{d}}=\left(f^{\mathrm{c}}\right)^{0.5} K_{\mathrm{sd}}\left(\left[\mathrm{CO}_{3}^{2-}\right]_{\mathrm{sat}}-\left[\mathrm{CO}_{3}^{2-}\right]\right)^{n_{\mathrm{sd}}}\left(c^{0}\right)^{-n_{\mathrm{sd}}}$

if $\left[\mathrm{CO}_{3}^{2-}\right]<\left[\mathrm{CO}_{3}^{2-}\right]_{\text {sat }}$

$\mathcal{R}^{\mathrm{d}}=0 \quad$ otherwise, where $K_{\mathrm{sd}}$ and $n_{\mathrm{sd}}$ are "effective" rate parameters (see below), $\left[\mathrm{CO}_{3}^{2-}\right]_{\text {sat }}$ and $\left[\mathrm{CO}_{3}^{2-}\right]$ is the carbonate ion concentration at calcite saturation and in the bottom water, respectively, and $c^{0}=1 \mathrm{~mol} \mathrm{~kg}^{-1}$ so that $\mathcal{R}^{\mathrm{d}}$ is in units of mol m${ }^{-2} \mathrm{yr}^{-1}$. It is important to note that the effective rate parameters $K_{\text {sd }}$ and $n_{\text {sd }}$ relate bottom water undersaturation to dissolution rate (Keir, 1982; Sundquist, 1986; Sigman et al., 1998; Zeebe and Zachos, 2007, see Table 3 for values). They are not to be confused with reaction parameters relating porewater undersaturation to dissolution rate such as the calcite reaction order $n$ (typically $n=4.5$ ).

Finally, an expression is needed for the calcite burial, $w^{\mathrm{c}}$, as a function of total burial $w$. The thickness of the pure calcite layer within $\Delta z(=w \Delta t)$ can be expressed as $f^{\mathrm{c}} \Delta z(1-\phi)$ but also as $1 \cdot \Delta h_{1}\left(1-\phi_{1}\right)$ (calcite fraction $=$ 1), which gives:

$\Delta h_{1}=f^{\mathrm{c}} \Delta z \frac{1-\phi}{1-\phi_{1}}$

or expressed per unit time as a rate:

$w^{\mathrm{c}}=f^{\mathrm{c}} w \frac{1-\phi}{1-\phi_{1}}$.

As a result, all rates have now been expressed by modelpredicted quantities and thus by inserting Eqs. (31), (32), and (36) into (30), the change in calcite content per time step can be computed. Because we took care of all individual porosities, the relationship between $\phi$ and $f^{\mathrm{c}}$, Eq. (29), is obeyed automatically.

In case of erosion $(w<0)$, it can be shown that:

$\frac{\mathrm{d} h_{1}}{\mathrm{~d} t}=-\left(1-f^{\mathrm{c} i}\right)(-w) \frac{1-\phi^{i}}{1-\phi_{0}}-r^{\mathrm{rs}}$

where $f^{\mathrm{c} i}$ and $\phi^{i}$ is the initial calcite fraction and porosity, respectively, and $r^{\mathrm{rs}}$ is the clay rain rate (see above). Subsurface sediment properties are hence based on the initial steady-state configuration (Fig. 4). For model applications that require multiple dissolution cycles with varying conditions during accumulation, the model should be restarted with appropriate initial conditions. The total dissolution of pure calcite can be derived as:

$\frac{\mathrm{d} h^{\mathrm{dc}}}{\mathrm{d} t}=\left[(-w)+r^{\mathrm{s}}\right]\left(1-\phi_{1}\right)$.

In other words, all calcite in $\Delta z$ and calcite rain is dissolved. In addition, calcite is being replaced by the clay in $\Delta z$ and by the clay rain (equivalent calcite is also dissolved).

Finally, the sediment model can also be formulated in terms of $f^{\mathrm{c}}$ by simply multiplying by a factor:

$\frac{\mathrm{d} f^{\mathrm{c}}}{\mathrm{d} t}=\frac{\mathrm{d} h_{1}}{\mathrm{~d} t} G^{-1}=\left(r^{\mathrm{cs}}-r^{\mathrm{d}}-w^{\mathrm{c}}\right) G^{-1}$,

where

$G=\frac{h_{\mathrm{s}}}{1-\phi_{1}}\left[(1-\phi)-f^{\mathrm{c}} \frac{\partial \phi}{\partial f^{\mathrm{c}}}\right]$ 
and

$\frac{\partial \phi}{\partial f^{\mathrm{c}}}=\frac{F_{\phi}\left(1-\phi_{0}\right)}{\left(1+f^{\mathrm{c}} F_{\phi}\right)^{2}}$

with $F_{\phi}=\left(\phi_{1}-\phi_{0}\right) /\left(1-\phi_{1}\right)$.

\subsection{Sediment model equations (all sediment boxes)}

Let $y_{n}$ be a subset of $\boldsymbol{y}$ (Eq. 1), representing the $\mathrm{CaCO}_{3}$ dry fraction $\left(f^{\mathrm{c}}\right)$ in sediment boxes at different depth levels in the different ocean basins. If the total number of depth levels is NSD and the total number of ocean basins is NOC (Table 1), then the total number of equations for all sediment boxes (total carbon) is NSD $\times$ NOC. Based on Eq. (39), the differential equation for the $\mathrm{CaCO}_{3}$ dry fraction in sediment box $j$ is (analogous equations hold for $\mathrm{Ca}^{13} \mathrm{CO}_{3}$ ):

$\frac{\mathrm{d} y_{n}}{\mathrm{~d} t}=\frac{\mathrm{d}\left(f_{j}^{\mathrm{c}}\right)}{\mathrm{d} t}=\left(r_{j}^{\mathrm{cs}}-r_{j}^{\mathrm{d}}-w_{j}^{\mathrm{c}}\right) G_{j}^{-1}$

where $j=1,2, \ldots$, NSD for the first ocean basin (Atlantic), $j=\mathrm{NSD}+1, \mathrm{NSD}+2, \ldots, 2 \mathrm{NSD}$ for the second ocean basin (Indian), and so on. In case of dissolution, $\mathrm{TCO}_{2}$ and $\mathrm{TA}$ are returned to the ocean, giving rise to the sediment source term in the ocean tracer equation (cf. Eq. 2):

$$
\begin{aligned}
V_{k}\left(\frac{\mathrm{d}\left[\mathrm{TCO}_{2}\right]_{k}}{\mathrm{~d} t}\right)_{\text {sed }} & =\sum_{j} A_{j}^{\mathrm{sed}} \mathcal{R}^{\mathrm{d}}{ }_{j} \\
V_{k}\left(\frac{\mathrm{d}[\mathrm{TA}]_{k}}{\mathrm{~d} t}\right)_{\text {sed }} & =2 \sum_{j} A_{j}^{\mathrm{sed}} \mathcal{R}_{j}^{\mathrm{d}}
\end{aligned}
$$

where each sum runs over all sediment boxes $j$ located within the area and depth range of ocean box $k$. The surface area of sediment box $j$ is denoted by $A_{j}^{\text {sed }}$.

\section{Miscellaneous}

\subsection{Ocean carbonate chemistry}

Carbonate chemistry parameters for modern seawater composition are calculated based on equilibrium constants on the total $p \mathrm{H}$ scale (Lueker et al., 2000; Zeebe and WolfGladrow, 2001). The $\mathrm{C}$ program uses a simplified and fast numerical routine to compute $\mathrm{CO}_{2}$ parameters from $\mathrm{TCO}_{2}$ and TA (Follows et al., 2006). If applied properly, the method yields accurate results that are essentially identical to those obtained with standard routines (Zeebe and Wolf-Gladrow, 2001). The method was originally devised to compute modern carbonate chemistry parameters in biogeochemical models where conditions change little between consecutive time steps (Follows et al., 2006). This is not necessarily always the case in LOSCAR and can lead to failure in rare cases. For instance, if the model is initiated with a very high TA/TCO ratio, the calculated $\mathrm{H}^{+}$concentration may become negative. The user is warned in such instances and is advised to change the initial conditions. Again, such cases are probably rare. In fairness, it should also be noted that non-standard chemistry conditions (which can occur in LOSCAR), are beyond the original intend of the method (Follows et al., 2006). Apart from the limitation mentioned above, the method is easy to implement, sufficiently accurate, and computationally efficient.

\subsection{Paleocene/Eocene ocean chemistry}

Paleocene/Eocene seawater conditions were different from modern conditions owing to factors such as temperature and major ion composition of seawater, including the seawater $\mathrm{Mg} / \mathrm{Ca}$ ratio (e.g. Tyrrell and Zeebe, 2004). These factors can significantly affect thermodynamic quantities such as equilibrium constants and solubility products, which in turn have a major impact on the predicted ocean carbonate chemistry and atmospheric $\mathrm{CO}_{2}$. The chemistry routines implemented in LOSCAR allow for variations in, for instance, temperature, salinity, and the concentrations of $\mathrm{Mg}^{2+}$ and $\mathrm{Ca}^{2+}$ in seawater. For example, due to warmer surface and bottom water temperatures in the late Paleocene and Eocene, the calcite saturation concentration at a bottom water temperature of $14-17^{\circ} \mathrm{C}$ during the PETM is quite different from the modern at $2^{\circ} \mathrm{C}$ (see Fig. 3 of Zeebe and Zachos, 2007). This effect is included in LOSCAR by using temperature-dependent equations for the solubility product of carbonate minerals (Mucci, 1983). Pressure corrections for solubility products and equilibrium constants are based on Millero (1995) and references therein; for the latest revisions, check: www.soest.hawaii.edu/oceanography/faculty/ zeebe_files/CO2_System_in_Seawater/csys.html.

Furthermore, the P/E-simulations use $\left[\mathrm{Mg}^{2+}\right]=$ $30 \mathrm{mmol} \mathrm{kg}^{-1}$ and $\left[\mathrm{Ca}^{2+}\right]=20 \mathrm{mmol} \mathrm{kg}^{-1}$ rather than the modern values of $\left[\mathrm{Mg}^{2+}\right]=53 \mathrm{mmol} \mathrm{kg}^{-1}$ and $\left[\mathrm{Ca}^{2+}\right]=10 \mathrm{mmol} \mathrm{kg}^{-1}$ (Tyrrell and Zeebe, 2004; Zeebe et al., 2009). The effect of seawater $\mathrm{Mg}^{2+}$ and $\mathrm{Ca}^{2+}$ on the first and second dissociation constant of carbonic acid is estimated using sensitivity coefficients (Ben-Yaakov and Goldhaber, 1973):

$s_{K^{*}}=\frac{\Delta K^{*} / K^{*}}{\Delta c_{i} / c_{i}}$

where $\Delta K^{*}$ is the change in the dissociation constant $K^{*}$ due to the relative change in concentration, $\Delta c_{i} / c_{i}$, of component $i$. Using $\Delta c / c=\left(c-c_{\mathrm{m}}\right) / c_{\mathrm{m}}$, where $\mathrm{m}=$ modern, it follows:

$\Delta K^{*}=s_{K^{*}} K^{*}\left(c / c_{\mathrm{m}}-1\right)$

and finally:

$K^{*}=K_{\mathrm{m}}^{*}+\Delta K_{\mathrm{Mg}^{2+}}^{*}+\Delta K_{\mathrm{Ca}^{2+}}^{*} \cdot$

Sensitivity parameters for the effect of $\mathrm{Mg}^{2+}$ and $\mathrm{Ca}^{2+}$ on $K^{*}$ are (Ben-Yaakov and Goldhaber, 1973): 


$$
\begin{array}{ccc}
s_{K_{1}^{*}}=155 \times 10^{-3} & s_{K_{2}^{*}}=442 \times 10^{-3} & \text { for } \mathrm{Mg}^{2+} \\
s_{K_{1}^{*}}=33.73 \times 10^{-3} & s_{K_{2}^{*}}=38.85 \times 10^{-3} & \text { for } \mathrm{Ca}^{2+}
\end{array}
$$

With these sensitivity parameters, and the modern and paleo-concentrations of $\mathrm{Mg}^{2+}$ and $\mathrm{Ca}^{2+}$ (see above), the correction to equilibrium constants (Eq. 47) can be applied.

Seawater $\mathrm{Mg}^{2+}$ and $\mathrm{Ca}^{2+}$ also affect the calcite solubility product, $K_{\mathrm{sp}}^{*}$, and thus the steady-state deep-sea $\left[\mathrm{CO}_{3}^{2-}\right]$. Following Mucci and Morse (1984), the stoichiometric solubility product drops with decreasing seawater $\mathrm{Mg} / \mathrm{Ca}$ ratio. In other words, Eocene $K_{\mathrm{sp}}^{*}$ would have been smaller and, given roughly constant deep-sea saturation state, $\left[\mathrm{CO}_{3}^{2-}\right]$ would also have been smaller than modern. The data of Mucci and Morse (1984) may be fitted to an equation of the form:

$K_{\mathrm{sp}}^{*}=K_{\mathrm{sp}, \mathrm{m}}^{*}\left[1-\alpha\left(x_{\mathrm{m}}-x\right)\right]$

where $\mathrm{m}=$ modern, $\alpha=0.0833$, and $x=\mathrm{Mg} / \mathrm{Ca}$. Using modern and $\mathrm{P} / \mathrm{E}$-values for $\left[\mathrm{Mg}^{2+}\right]$ and $\left[\mathrm{Ca}^{2+}\right]$ as given above, the stoichiometric solubility product of calcite would have been reduced by about $30 \%$, compared to modern.

Another important consequence of changes in oceanic $\mathrm{Ca}^{2+}$, for instance, is its effect on the ocean carbon inventory. The long-term carbon inventory and carbonate chemistry of the ocean-atmosphere system is controlled by atmospheric $\mathrm{CO}_{2}$ and the balance between riverine flux and carbonate burial (Zeebe and Caldeira, 2008). Carbonate burial is tied to the deep-sea carbonate saturation, which is proportional to the product of $\left[\mathrm{Ca}^{2+}\right] \times\left[\mathrm{CO}_{3}^{2-}\right]$. If oceanic $\left[\mathrm{Ca}^{2+}\right]$ doubles at constant saturation state, $\left[\mathrm{CO}_{3}^{2-}\right]$ would drop by $50 \%$ (even more if the effect of $\mathrm{Mg} / \mathrm{Ca}$ on $K_{\mathrm{sp}}^{*}$ is accounted for). For example, $\left[\mathrm{CO}_{3}^{2-}\right]$ prior to the PETM was hence much lower than modern if Paleocene/Eocene $\left[\mathrm{Ca}^{2+}\right]$ was $20 \mathrm{mmol} \mathrm{kg}^{-1}$. In the model, this leads to a pre-PETM ocean carbon inventory that is similar to the modern value, despite a higher baseline atmospheric $\mathrm{CO}_{2}$ at the time.

\subsection{Temperature sensitivity}

The initial temperature of each individual ocean box is set at the start of the run. Throughout the run, temperature can be held constant, be manipulated based on user input, or be computed based on a simple expression for the sensitivity of temperature to changes in atmospheric $\mathrm{CO}_{2}$ as calculated by the model (cf. Archer, 2005). In order to provide a flexible and numerically stable option, the $\mathrm{C}$ version of the program includes temperature as an ocean tracer variable. The temperature of ocean box $k\left(T_{\mathrm{C}, k}\right.$ in $\left.{ }^{\circ} \mathrm{C}\right)$ is assumed to respond to a change in $p \mathrm{CO}_{2}$ with a certain time lag and relax towards equilibrium temperature. The equilibrium temperature of box $k$ is given by:
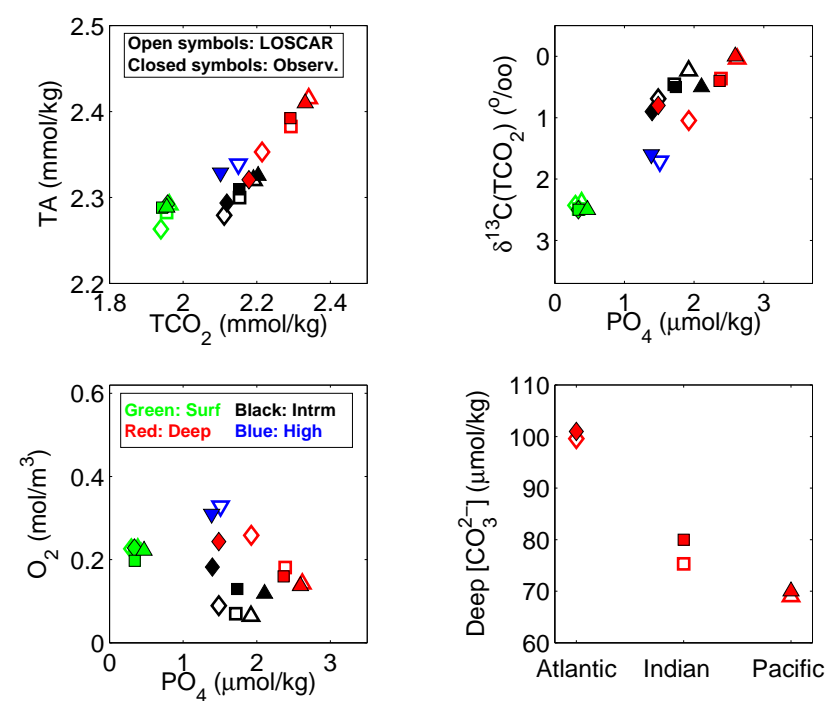

Fig. 5. Computed model tracers and observations used for LOSCAR parameter tuning for modern (preindustrial) configuration, see text for details.

$T_{\mathrm{C}, k}^{\mathrm{eq}}=T_{\mathrm{C}, k}^{0}+s \ln \left(p \mathrm{CO}_{2} / p \mathrm{CO}_{2}^{0}\right) / \ln (2)$,

where the superscript " 0 " refers to the initial (steady-state) temperature and $p \mathrm{CO}_{2}$, respectively, and $s$ is the prescribed temperature increase per doubling of atmospheric $\mathrm{CO}_{2}$. The parameter $s$ as used here is conceptually similar to what is generally referred to as "climate sensitivity". However, the precise meaning of $s$ will have to be defined properly for each specific application in the context of the time scales and feedbacks involved (see Zeebe, 2011).

The differential equation for the temperature of ocean box $k$ then reads:

$\frac{\mathrm{d}\left(T_{\mathrm{C}, k}\right)}{\mathrm{d} t}=\left(T_{\mathrm{C}, k}^{\mathrm{eq}}-T_{\mathrm{C}, k}\right) / \tau_{n}$

where $\tau_{n}$ is the relaxation time, which can take on three different values depending on whether $k$ refers to a surface, intermediate, or deep box (Table 2).

\subsection{Numerics}

As mentioned above, the equations solved in LOSCAR are typically stiff and require an appropriate solver for the problem. The LOSCAR C-version uses a fourth-order Rosenbrock method with automatic stepsize adjustment (Press et al., 1992). For these kind of solvers, it is critical to scale the variables properly. Thus, variables have been scaled to order 1 , if necessary, by multiplying by arbitrary factors before passing to the solver. This includes, for instance, atmospheric carbon and temperature (see Sects. 5 and 7.3).

The carbonate dissolution rate, $\mathcal{R}^{\mathrm{d}}$ is proportional to the square root of the $\mathrm{CaCO}_{3}$ fraction $f^{\mathrm{c}}$ (Eq. 33). It turned out 

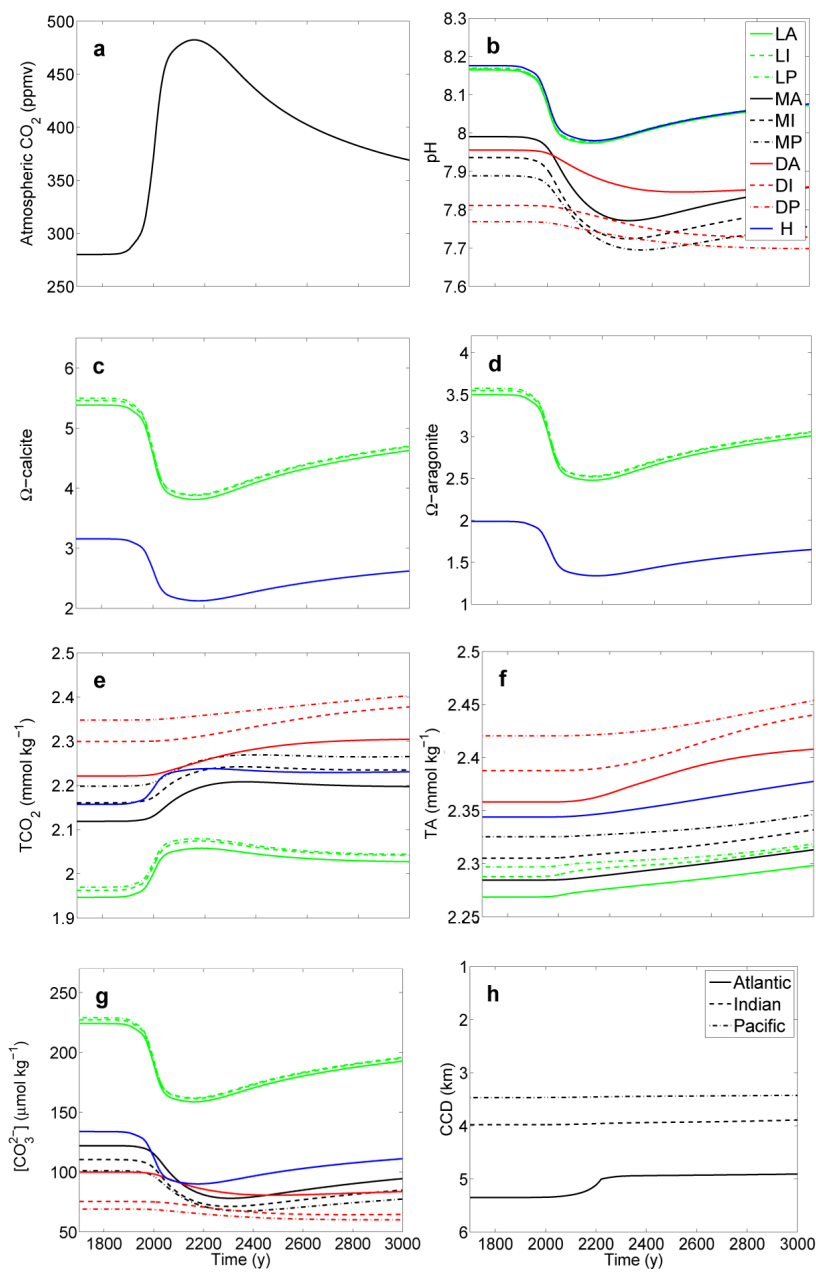

Fig. 6. Example of a fossil fuel emission scenario simulated in LOSCAR: total release of $1000 \mathrm{Pg} \mathrm{C}$ over $500 \mathrm{yr}$ (see Zeebe et al., 2008). Results shown slightly differ from those in Zeebe et al. (2008) because ocean temperature was held constant here for simplicity. $\mathrm{L}=$ Low-latitude, $\mathrm{M}=$ interMediate, $\mathrm{D}=$ Deep, $\mathrm{H}=$ Highlatitude. $\mathrm{A}=$ Atlantic, $\mathrm{I}=$ Indian, $\mathrm{P}=$ Pacific. Note that the step in the Atlantic calcite compensation depth $(\mathrm{CCD}$, panel $\mathbf{h})$ is due to the spacing of sediment-box depth levels in the model (adding more sediment boxes would make the curve smoother).

that during strong dissolution, $f^{\mathrm{c}}$ occasionally became negative when the $\mathrm{CaCO}_{3}$ fraction approached zero. This issue has been eliminated (in most cases) by using a linear relationship between $f^{\mathrm{c}}$ and $\mathcal{R}^{\mathrm{d}}$ when $f^{\mathrm{c}}$ drops below a certain threshold value $f_{\mathrm{sml}}^{\mathrm{c}}$. The threshold value can be changed by the user and should be increased if $f^{\mathrm{c}}$ still becomes negative during a run. Another option is to increase the solver accuracy by reducing the value of $\varepsilon_{\text {slv }}$ (the default value is usually not very accurate).

LOSCAR is quick. Running the fossil fuel scenario over $1250 \mathrm{yr}$ (Fig. 6) using the LOSCAR C code compiled under Linux with gec 4.4.3, without optimization and default $\varepsilon_{\text {slv }}$, takes less than $2 \mathrm{~s}$ wall clock time on a current standard desktop machine with Intel Core2 Duo E8500 @3.16 GHz (no other CPU-demanding processes running). The computational efficiency makes LOSCAR an ideal tool for multiparameter variations that require a large number of model runs (e.g. Zeebe et al., 2008, 2009).

\section{Tuning}

In order for LOSCAR to provide model output that resembles observations, several model parameters require tuning. This includes mixing coefficients, biological export fluxes, remineralization fraction (intermediate vs. deep box), rain ratio, and water column dissolution (see Table 2). The tuning is based on comparison between model-predicted variables and modern observations. For example, parameters were tuned by requiring the ocean tracer variables $\mathrm{TCO}_{2}$ and $\mathrm{TA}$ in the various model boxes to match GLODAP data, averaged over the area and depth range of the corresponding boxes (Key et al., 2004). Note that $\mathrm{TCO}_{2}$ data were corrected for anthropogenic carbon by subtracting 45 and $25 \mu \mathrm{mol} \mathrm{kg}-1$ from the surface and intermediate values, respectively (see below for $\delta^{13} \mathrm{C}$-corrections). The agreement between model and data is satisfactory (see Fig. 5). As a result, the global preindustrial $\mathrm{TCO}_{2}$ inventory in LOSCAR is $35830 \mathrm{Pg} \mathrm{C}$ vs. $35760 \mathrm{Pg} \mathrm{C}$ based on GLODAP data (Key et al., 2004). Similarly, model $\mathrm{PO}_{4}$ and oxygen were compared to data summarized in the World Ocean Atlas (WOA05, 2005). Again, the agreement between model and data is adequate, except perhaps for the oxygen content in intermediate boxes, which appears to be underestimated by the model. This could be improved. However, it would come at the expense of a larger mismatch in the deep boxes. This was avoided because for our LOSCAR applications so far, the properties of the deep boxes were more important than those of the intermediate boxes.

Another variable used for parameter tuning is the stable carbon isotope composition of $\mathrm{TCO}_{2}\left(\delta^{13} \mathrm{C}_{\mathrm{TCO}_{2}}\right)$, which was matched to the data of Kroopnick (1985). Note that due to the ocean's uptake of fossil fuel carbon (which is isotopically light, i.e. depleted in ${ }^{13} \mathrm{C}$ ), the ocean's $\delta^{13} \mathrm{C}_{\mathrm{TCO}_{2}}$ is continuously dropping (so-called Suess effect). Thus, for preindustrial tuning, the early $\delta^{13} \mathrm{C}$-data sets are more useful than the most recent ones, which are increasingly contaminated with anthropogenic carbon. Nevertheless, Kroopnick (1985) estimated that surface ocean $\delta^{13} \mathrm{C}_{\mathrm{TCO}_{2}}$ had already dropped by $\sim 0.5 \%$ and that the average $\delta^{13} \mathrm{C}_{\mathrm{TCO}_{2}}$ of the preindustrial surface ocean was about $2.5 \%$. This surface value was used for model parameter tuning (Fig. 5). As a result, the preindustrial $\delta^{13} \mathrm{C}$ of atmospheric $\mathrm{CO}_{2}$ is $-6.38 \%$ in LOSCAR vs. -6.30 to $-6.40 \%$ based on ice core and firn data (e.g. Francey et al., 1999).

Adequate model values for the steady-state carbonate ion concentration in the deep boxes are important for both the ocean and the sediment model component. After parameter 
tuning, the preindustrial deep-sea $\left[\mathrm{CO}_{3}^{2-}\right]$ as predicted by LOSCAR and calculated based on GLODAP data (Key et al., 2004) are in good agreement (Fig. 5). The preindustrial inventory of $\mathrm{CaCO}_{3}$ in the seafloor-bioturbated sediment layer (in units of carbon) is about $800 \mathrm{PgC}$, close to the value of more complex models (e.g. Archer et al., 1998).

In summary, after model-data comparison including all variables shown in Fig. 5, the values for the parameters labeled "tuned" in Table 2 were obtained. The preindustrial (steady-state) $p \mathrm{CO}_{2}$ in the model was set to $280 \mu \mathrm{atm}$ by assigning this value to $p \mathrm{CO}_{2}^{0}$, which drives the system towards the desired steady-state $p \mathrm{CO}_{2}$ via the silicate weathering equation (Eq. 17). Regarding the Paleocene/Eocene model setup, several key parameters such as deep-sea $\left[\mathrm{CO}_{3}^{2-}\right]$ and the calcite compensation depth (CCD) before and during the PETM have been discussed elsewhere and are not repeated here (see Zeebe et al., 2009, Supplementary Information). In the default LOSCAR setup, the CCD is taken as the depth at which the $\mathrm{CaCO}_{3}$ sediment content is reduced to $10 \mathrm{wt}$ \% (Ridgwell and Zeebe, 2005). The pre-PETM inventory of $\mathrm{CaCO}_{3}$ in the seafloor-bioturbated sediment layer (in units of carbon) is about $620 \mathrm{Pg} \mathrm{C}$. The initial (steady-state) partial pressure of atmospheric $\mathrm{CO}_{2}$ was set to $1000 \mu$ atm in our $\mathrm{P} / \mathrm{E}$-simulations. Although this value falls within the (large) range of available proxy estimates, it is somewhat arbitrary. The user is welcome to change the initial $p \mathrm{CO}_{2}$ value in the P/E-setup.

\section{Input/output examples}

In the following, two input/output examples will be presented, one dealing with anthropogenic fossil fuel emissions, the other with carbon release during the PETM. The input files for these examples are included in the model package.

\subsection{Fossil fuel emission scenario}

LOSCAR can read in files that supply a time series of fossil fuel emissions in order to project future changes in atmospheric $\mathrm{CO}_{2}$, surface ocean $\mathrm{pH}$, calcite and aragonite saturation, and other variables (cf. Zeebe et al., 2008, Supporting Online Material). For example, Fig. 6 shows results obtained with LOSCAR for a fossil fuel emission scenario with a total carbon release of $1000 \mathrm{PgC}$ over $500 \mathrm{yr}$. Note that the results differ slightly from those in Zeebe et al. (2008) because ocean temperature was held constant here for simplicity. The initial conditions from which the scenario was started are the preindustrial steady-state conditions shown in Fig. 5. No changes in the biological pump were assumed ( $\mathrm{PO}_{4}$ is constant). The temperature of the low- and highlatitude box is 20 and $2{ }^{\circ} \mathrm{C}$, respectively (Table 2 ). This temperature difference is mostly responsible for the difference in carbonate ion concentration $\left(\left[\mathrm{CO}_{3}^{2-}\right]\right)$ and saturation state $(\Omega)$ between low- and high-latitude surface boxes. Note that
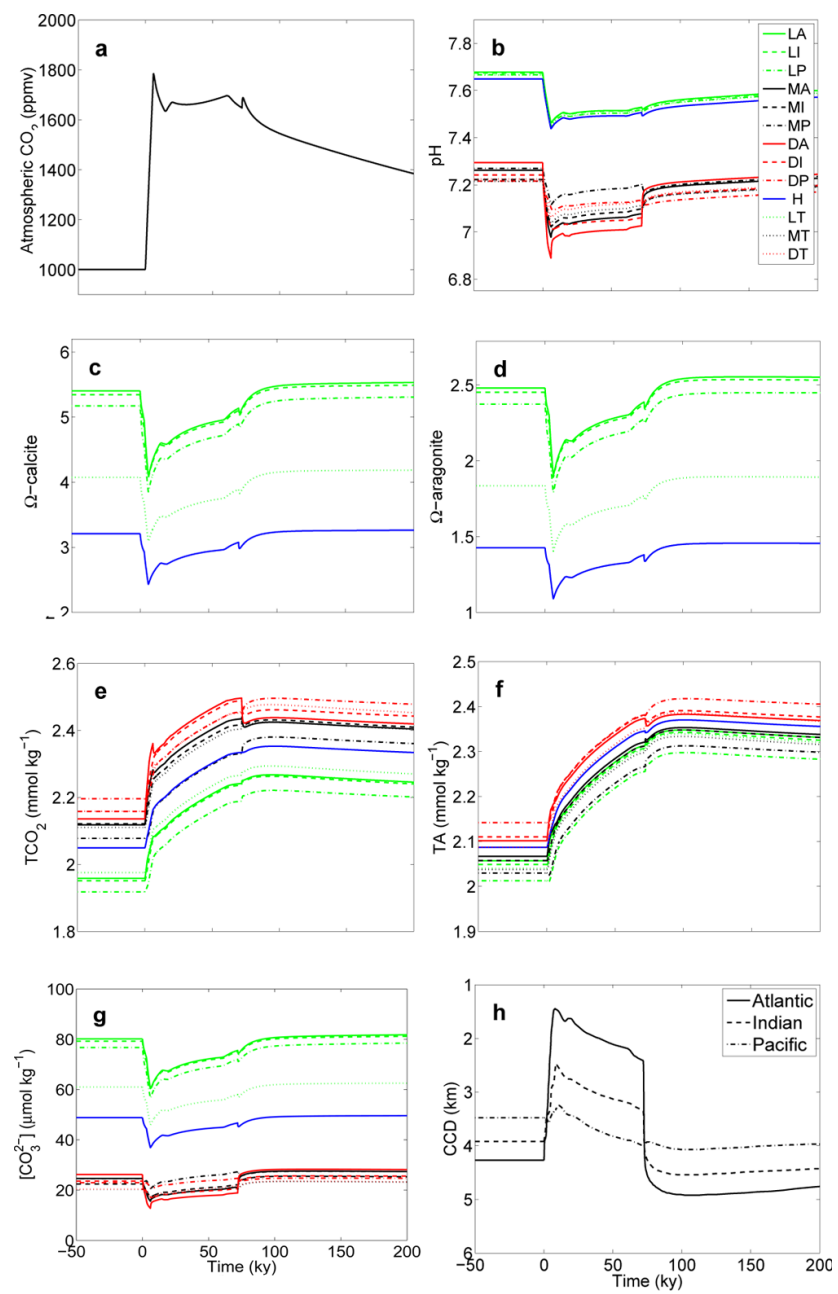

Fig. 7. Example of a PETM carbon release scenario simulated in LOSCAR: initial release of $3000 \mathrm{PgC}$ over a few thousand years (see Zeebe et al., 2009). L = Low-latitude, $M=$ interMediate, $\mathrm{D}=$ Deep, $\mathrm{H}=$ High-latitude. $\mathrm{A}=$ Atlantic, $\mathrm{I}=$ Indian, $\mathrm{P}=$ Pacific, $\mathrm{T}=$ Tethys. See text for details.

while $\mathrm{TCO}_{2}$ in the surface boxes responds immediately to the fossil fuel carbon release, there is a delay in TA, which only starts rising once sediment dissolution commences and the calcite compensation depth (CCD) starts shallowing (cf. Ilyina et al., 2009).

\subsection{Paleocene-Eocene Thermal Maximum}

Using appropriate boundary conditions, LOSCAR can also be used to simulate time intervals or events of the past such as the PETM. During the PETM, a large mass of carbon was released into Earth's surface reservoirs (e.g. Dickens et al., 1995; Zachos et al., 2005; Dickens, 2011), while surface temperatures rose by $5-9{ }^{\circ} \mathrm{C}$ within a few thousand years. Figure 7 shows results for a PETM scenario with an initial carbon input of $3000 \mathrm{PgC}$ over a few thousand years, 
which yields close agreement with observations (for more details, see Zeebe et al., 2009). Note that the time interval of the integration now covers $200 \mathrm{kyr}$ ( $t=0$ refers to the $\mathrm{P} / \mathrm{E}$ boundary), rather than a few millennia as in the previous example. Changes in boundary conditions compared to the modern setup include a Paleocene/Eocene bathymetry (Bice and Marotzke, 2002), addition of the Tethys ocean, and different seawater chemistry (see Sect. 7.2). Furthermore, the PETM simulations use different initial conditions for e.g. temperature, steady-state $p \mathrm{CO}_{2}^{0}$, weathering fluxes (Tables 2 and 3), and different steady-state circulation patterns (see Fig. 2). Note also that a transient contribution of North Pacific Deep Water (not shown) during the PETM main phase was included in our simulations (Bice and Marotzke, 2002; Zeebe et al., 2009). The Southern Ocean source remains active during the event but is reduced relative to its preevent strength (down to $7.5 \mathrm{~Sv}$ ). The transport associated with the North Pacific source is $6.25 \mathrm{~Sv}$. This overall reduced global overturning circulation during the PETM main phase is consistent with a sluggish circulation found in a fully coupled atmosphere-ocean general circulation model with Eocene boundary conditions at high atmospheric $\mathrm{CO}_{2}$ concentrations (Lunt et al., 2010).

At steady-state $p \mathrm{CO}_{2}^{0}$ of $1000 \mu \mathrm{atm}$, but similar carbonate mineral saturation state as in the modern ocean, the steadystate $\mathrm{pH}$ of the Paleocene/Eocene ocean would have been lower than modern (Fig. 7). Because of higher seawater $\mathrm{Ca}^{2+}$ and the effect of $\mathrm{Mg} / \mathrm{Ca}$ on the solubility product of calcite, the initial carbonate ion concentration in the P/E-simulations is substantially lower than in the modern ocean (cf. Sect. 7.2). As a result, steady-state $\mathrm{TCO}_{2}$ and TA are similar to modern values despite higher $p \mathrm{CO}_{2}$ (Fig. 7). Note that the Atlantic CCD shoals dramatically during the event, while there is little response in the Pacific CCD, consistent with observations (Zachos et al., 2005; Zeebe et al., 2009; Leon-Rodriguez and Dickens, 2010). The "overshoot" of the CCD, i.e. the fact that its position is deeper at $t>80 \mathrm{kyr}$ than its initial position, is a direct consequence of the weathering feedback (see Sect. 4) and is also in agreement with observations (e.g. Kelly et al., 2005). At $t>80 \mathrm{kyr}$, atmospheric $p \mathrm{CO}_{2}$ is still elevated over the initial $p \mathrm{CO}_{2}^{0}$ (Fig. 7), which causes enhanced weathering of carbonates and silicates. The enhanced weathering raises the ocean's saturation state and deepens the CCD until a quasi steady-state of riverine flux and burial has been established. The quasi steady-state ( $t>80 \mathrm{kyr}$ ) must be maintained at a CCD deeper than the initial depth (because of enhanced burial) until atmospheric $p \mathrm{CO}_{2}$ and weathering fluxes have returned to their initial steady-state values. This explains the "overshoot" of the CCD.

\section{Model intercomparison: lifetime of fossil fuel $\mathrm{CO}_{2}$}

Several carbon cycle processes as simulated in LOSCAR can be quantitatively compared to other models by examining the

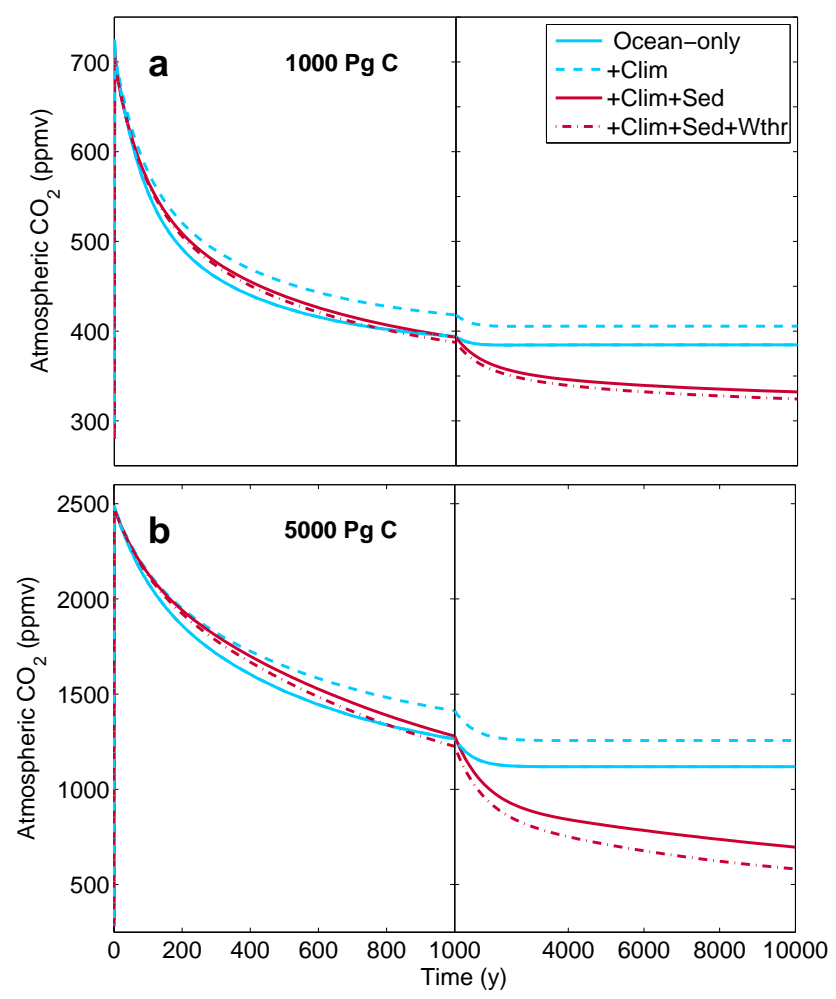

Fig. 8. LOSCAR simulations of the long tail of the lifetime of fossil fuel $\mathrm{CO}_{2}$ (cf. Archer et al., 2009). (a) Simulated atmospheric $\mathrm{CO}_{2}$ concentrations in response to a $1000 \mathrm{Pg} \mathrm{C}$ pulse, (b) $5000 \mathrm{Pg} \mathrm{C}$ pulse. "Ocean-only" runs include ocean $\mathrm{CO}_{2}$ uptake only (sediments off, weathering feedback off). "+Clim" runs include an additional temperature feedback of $3{ }^{\circ} \mathrm{C}$ per $\mathrm{CO}_{2}$ doubling (see Sect. 7.3). "+Clim+Sed" runs include the temperature and sediment feedback (weathering fluxes are held constant). "+Clim+Sed+Wthr" runs include the temperature, sediment, and weathering feedback.

numerical results. For instance, Archer et al. (2009) conducted a model intercomparison focusing on the long tail of the lifetime of fossil fuel $\mathrm{CO}_{2}$. The results of that study allow comparison of carbon cycle dynamics between models, including processes such as ocean uptake of fossil fuel $\mathrm{CO}_{2}$, reaction of $\mathrm{CO}_{2}$ with deep-sea sediment $\mathrm{CaCO}_{3}$, and the longterm effects of weathering on fossil fuel neutralization. The model intercomparison included two experiments in which pulses of 1000 and $5000 \mathrm{PgC}$ were added to the models' atmospheres and the subsequent model response was followed over 10000 yr. For each of the pulses, the effects of various feedbacks were tested, including changes in temperature/climate, sediment response, and weathering.

The results of the corresponding model experiments with LOSCAR are shown in Fig. 8. Generally, the atmospheric $\mathrm{CO}_{2}$ levels over time as calculated with LOSCAR fall in the lower to mid range of the atmospheric $\mathrm{CO}_{2}$ levels calculated with the nine models compared by Archer et al. (2009). 
LOSCAR's equilibration time $(\tau)$ for ocean uptake was obtained by fitting an exponential, $\propto e^{-t / \tau}$, to the model $p \mathrm{CO}_{2}$ over the first few hundred years for the ocean-only case (no changes in climate, sediments off, weathering off). This yields values for $\tau$ of $216 \mathrm{yr}$ and $500 \mathrm{yr}$ for the 1000 and $5000 \mathrm{Pg} \mathrm{C}$ pulse, respectively. The corresponding average of all models studied by Archer et al. (2009) is $250 \mathrm{yr}$ and $450 \mathrm{yr}$, respectively. When a temperature feedback of $3^{\circ} \mathrm{C}$ per $\mathrm{CO}_{2}$ doubling is included in LOSCAR (see Sect. 7.3), $\tau$ for ocean uptake increases to $267 \mathrm{yr}$ and $595 \mathrm{yr}$ for the 1000 and $5000 \mathrm{Pg} \mathrm{C}$ pulse, respectively. In LOSCAR, the increased equilibration time for ocean $\mathrm{CO}_{2}$ uptake is solely due to higher ocean temperature, which reduces the solubility of $\mathrm{CO}_{2}$ and leaves a larger fraction of $\mathrm{CO}_{2}$ in the atmosphere. Some of the models analyzed by Archer et al. (2009) show larger effects of climate change on ocean uptake, presumably due to additional changes in ocean circulation and mixing.

The next step in the process of fossil fuel neutralization after ocean uptake is reaction of $\mathrm{CO}_{2}$ with carbonate sediments in the deep sea, promoting $\mathrm{CaCO}_{3}$ dissolution. In LOSCAR, it takes several millennia for the carbonate content in deepsea sediments to reach its minimum. In contrast to ocean uptake, however, an exponential is a poor fit to the model's $p \mathrm{CO}_{2}$ decline during the time interval of carbonate dissolution. Nevertheless, in the time window from 1000 to $3000 \mathrm{yr}$, and exponential fit yields an approximate response time of $\sim 4200 \mathrm{yr}$ and $\sim 3800 \mathrm{yr}$ for the 1000 and $5000 \mathrm{Pg} \mathrm{C}$ pulse, respectively. For comparison, the $\mathrm{CaCO}_{3}$ response time scale of the models tested by Archer et al. (2009) varies roughly between 3000 and $8000 \mathrm{yr}$. The final step of fossil fuel neutralization is enhanced weathering of carbonate and silicate rocks on the continents, which restores $p \mathrm{CO}_{2}$ to its longterm steady-state value (see Sect. 4). Note that constant carbonate and silicate weathering fluxes are also included in the LOSCAR experiments labeled "+Sed" in Fig. 8. However, experiments labeled "+Wthr" include a weathering feedback with enhanced weathering fluxes at elevated $p \mathrm{CO}_{2}$. On a time scale of $10^{4} \mathrm{yr}$, the effect on fossil fuel neutralization from the addition of the weathering feedback is smaller than that from the addition of sediments (Fig. 8). This is consistent with the results of Archer et al. (2009). However, on time scales $>10^{5} \mathrm{yr}$, the silicate weathering feedback becomes the dominant effect. Unfortunately, the parameters that determine the strength of the weathering feedback are not well constrained, which can lead to significant differences in calculated atmospheric $\mathrm{CO}_{2}$ levels on time scales $>10^{5} \mathrm{yr}$ (e.g. Uchikawa and Zeebe, 2008)

In addition to simple carbon input experiments, one may also compare the average ocean $\mathrm{CO}_{2}$ uptake between models from 1990 to 2000 using historical fossil fuel emissions. The observed uptake during the $1990 \mathrm{~s}$ was $2.2 \pm 0.4 \mathrm{PgC} \mathrm{yr}^{-1}$ (IPCC, 2007). With a few exceptions, the models included in the intercomparison by Archer et al. (2009) cluster around 2.0 $\mathrm{PgC} \mathrm{yr}^{-1}$; LOSCAR's value is $1.9 \mathrm{PgC} \mathrm{yr}^{-1}$. The bottom line is that in terms of ocean $\mathrm{CO}_{2}$ uptake, a number of carbon cycle models - including LOSCAR - behave quite similar. This is not too surprising, given that ocean $\mathrm{CO}_{2}$ uptake is, to a large degree, controlled by seawater carbonate chemistry, which is well known. In addition, calibration of the models is aided by the availability of a tuning target, namely, the observed ocean uptake. The sediment response among different models is more difficult to gauge due to several factors including different sediment model formulations, uncertainties in dissolution rate parameters (e.g. Morse and Mackenzie, 1990), and lack of a suitable tuning target based on observations. Nevertheless, all models tested in Archer et al. (2009) and LOSCAR agree that fossil fuel $\mathrm{CO}_{2}$ neutralization via reaction with sedimentary $\mathrm{CaCO}_{3}$ will take several millennia. Towards the end of the long tail of the $\mathrm{CO}_{2}$ lifetime, carbon will be slowly removed from the atmosphere by enhanced silicate weathering. However, it will likely take tens to hundreds of thousands of years until $p \mathrm{CO}_{2}$ will return to climatically relevant levels of, say, $400 \mu$ atm in the future.

\section{Model limitations and future developments}

As mentioned above, LOSCAR is designed to compute the partitioning of carbon between ocean, atmosphere, and sediments on time scales ranging from centuries to millions of years. LOSCAR is not designed to address carbon cycle problems on time scales much shorter than centuries. LOSCAR is also not suitable for tackling problems that require fine horizontal and/or vertical resolution. For instance, attempting to model the interannual variability of air-sea $\mathrm{CO}_{2}$ exchange in the Weddell Sea with LOSCAR would obviously be silly. On the other hand, LOSCAR does a reasonable job, for example, in calculating the globally averaged ocean $\mathrm{CO}_{2}$ uptake over the decade from 1990 to 2000 (see Sect. 10). At present, LOSCAR includes one generic highlatitude box and does not explicitly resolve differences, for instance, between deep water formation sites in the North Atlantic and the Southern Ocean. As a result of this and the current modern ocean configuration in LOSCAR, water mass boundaries, say, between North Atlantic Deep Water and Antarctic Bottom Water are not being resolved. However, given LOSCAR's flexible ocean configuration, additional ocean boxes may be included to accommodate such features. In general, LOSCAR's components are designed to efficiently compute global carbon cycle dynamics. This philosophy also applies to the sediment model, which calculates changes in $\% \mathrm{CaCO}_{3}$ at low computational costs. On the contrary, if the goal is to model, for example, the detailed effects of organic carbon and methane oxidation on sediment pore water profiles, a different tool is required (e.g. Zeebe, 2007).

Future versions of LOSCAR may include new features such as additional boxes and tracers such as radiocarbon. Because a meaningful ${ }^{14} \mathrm{C}$ model-data comparison generally requires multiple high-latitude surface boxes, radiocarbon should be included after at least one more high-latitude 
surface box has been added. Other future changes may include addition of respiratory-driven carbonate dissolution in sediments. Respiratory dissolution could be important, for instance, for the steady-state position of the lysocline. However, respiratory dissolution is unlikely to have a significant effect on the evolution of sediment $\% \mathrm{CaCO}_{3}$ during massive dissolution events such as those caused by large carbon inputs from e.g. fossil-fuel burning or during the PETM. Because these events have hitherto been the modeling targets for our LOSCAR applications, respiratory dissolution has not been included. Future versions of LOSCAR should consider this feature when processes are modeled for which respiratory dissolution is critical. Finally, I emphasize that LOSCAR's strength is its simplicity and efficiency, which will remain a priority in future developments. For the potential user this could mean that a different model needs to be considered altogether, if LOSCAR does not suit the problem at hand.

\section{Summary}

LOSCAR is a useful tool to tackle carbon cycle problems on various time scales as demonstrated in earlier applications that dealt with future projections of ocean chemistry and weathering, $p \mathrm{CO}_{2}$ sensitivity to carbon cycle perturbations throughout the Cenozoic, and carbon/calcium cycling during the PETM (Zeebe et al., 2008; Zachos et al., 2008; Zeebe et al., 2009; Uchikawa and Zeebe, 2008; Stuecker and Zeebe, 2010; Uchikawa and Zeebe, 2010; Komar and Zeebe, 2011; Zeebe and Ridgwell, 2011; Zeebe, 2012). The present contribution has provided a coherent description of the LOSCAR model. The description will hopefully be beneficial to the readership of the journal, as well as users of the model. I anticipate that future applications will reveal the full spectrum of problems suitable to be studied with LOSCAR. The LOSCAR source code in $\mathrm{C}$ can be obtained from the author by sending a request to loscar.model@gmail.com.

Acknowledgements. I thank Guy Munhoven and Gary Shaffer (reviewers), and Andy Ridgwell (tachyonic editor) for their comments, which have improved the ms. Jim Zachos was instrumental in sparking my interest in the PETM, which prompted part of LOSCAR's model development. C. Chun and M. Zeebe provided insight into the KATJES algorithm. I also thank Karen Bice for providing the P/E-bathymetry.

Edited by: A. Ridgwell

\section{References}

Archer, D. E.: An atlas of the distribution of calcium carbonate in sediments of the deep sea, Global Biogeochem. Cy., 10, 159174, 10.1029/95GB03016, 1996.

Archer, D. E.: Fate of fossil fuel $\mathrm{CO}_{2}$ in geologic time, J. Geophys. Res., 110, 1012, C09S05, doi:10.1029/2004JC002625, 2005.

Archer, D. E., Kheshgi, H., and Maier-Reimer, E.: Dynamics of fossil fuel $\mathrm{CO}_{2}$ neutralization by marine $\mathrm{CaCO}_{3}$, Global Biogeochem. Cy., 12, 259-276, 1998.

Archer, D. E., Eby, M., Brovkin, V., Ridgwell, A., Cao, L., Mikolajewicz, U., Caldeira, K., Matsumoto, K., Munhoven, G., Montenegro, A., and Tokos, K.: Atmospheric lifetime of fossil fuel carbon dioxide, Ann. Rev. Earth Planet. Sci., 37, 117-134, doi:10.1146/annurev.earth.031208.100206, 2009.

Ben-Yaakov, S. and Goldhaber, M. B.: The influence of sea water composition on the apparent constants of the carbonate system, Deep-Sea Res., 20, 87-99, 1973.

Berner, R. A., Lasaga, A. C., and Garrels, R. M.: The carbonatesilicate geochemical cycle and its effect on atmospheric carbon dioxide over the past 100 million years, Am. J. Sci., 283, 641683, 1983.

Bice, K. L. and Marotzke, J.: Could changing ocean circulation have destabilized methane hydrate at the $\mathrm{Pa}$ leocene/Eocene boundary?, Paleoceanography, 17, 1018, doi:10.1029/2001PA000678, 2002.

Broecker, W. S. and Peng, T.-H.: The role of $\mathrm{CaCO}_{3}$ compensation in the glacial to interglacial atmospheric $\mathrm{CO}_{2}$ change, Global Biogeochem. Cy., 1, 15-29, 1987.

Broecker, W. S. and Peng, T.-H.: Greenhouse Puzzles: Keelings's World, Martin's World, Walker's World, 2nd Edn., Eldigio Press, Palisades, New York, 1998.

Broecker, W. S. and Takahashi, T.: Neutralization of fossil fuel $\mathrm{CO}_{2}$ by marine calcium carbonate, in: The Fate of Fossil Fuel $\mathrm{CO}_{2}$ in the Oceans, edited by: Anderson, N. R. and Malahoff, A., Plenum Press, New York, 213-241, 1977.

deMenocal, P. B., Ruddiman, W. F., and Pokras, E. M.: Influences of high- and low-latitude processes on African climate: Pleistocene eolian records from equatorial Atlantic Ocean Drilling Program Site 663, Paleoceanography, 8, 209-242, 1993.

Dickens, G. R.: Down the Rabbit Hole: toward appropriate discussion of methane release from gas hydrate systems during the Paleocene-Eocene thermal maximum and other past hyperthermal events, Clim. Past, 7, 831-846, doi:10.5194/cp-7-831-2011, 2011.

Dickens, G. R., O’Neil, J. R., Rea, D. K., and Owen, R. M.: Dissociation of oceanic methane hydrate as a cause of the carbon isotope excursion at the end of the Paleocene, Paleoceanography, 10, 965-971, 1995.

Feely, R. A., Sabine, C. L., Lee, K., Millero, F. J., Lamb, M. F., Greeley, D., Bullister, J. L., Key, R. M., Peng, T.-H., Kozyr, A., Ono, T., and Wong, C. S.: In situ calcium carbonate dissolution in the Pacific Ocean, Global Biogeochem. Cy., 16, 1144, doi:10.1029/2002GB001866, 2002.

Follows, M. J., Ito, T., and Dutkiewicz, S.: On the solution of the carbonate chemistry system in ocean biogeochemistry models, Ocean Model., 12, 290-301, doi:10.1016/j.ocemod.2005.05.004, 2006.

Francey, R. J., Allison, C. E., Etheridge, D. M., Trudinger, C. M., 
Enting, I. G., Leuenberger, M., Langenfelds, R. L., Michel, E., and Steele, L. P.: A 1000-year high precision record of $\delta^{13} \mathrm{C}$ in atmospheric $\mathrm{CO}_{2}$, Tellus, 51B, 170-193, 1999.

Hayes, J. M.: Factors controlling ${ }^{13} \mathrm{C}$ contents of sedimentary organic compounds: Principles and evidence, Mar. Geol., 113, 111-125, 1993.

Herbert, T. D. and Mayer, L. A.: Long climatic time series from sediment physical property measurements, J. Sed. Petrol., 61, 1089-1108, 1991.

Ilyina, T., Zeebe, R. E., Maier-Reimer, E., and Heinze, C.: Early detection of ocean acidification effects on marine calcification, Global Biogeochem. Cy., 23, GB1008, doi:10.1029/2008GB003278, 2009.

IPCC: Intergovernmental Panel on Climate Change, Climate Change 2007: The Physical Science Basis, edited by: Solomon, S., Qin, D., Manning, M., Chen, Z., Marquis, M., Averyt, K. B., Tignor, M., and Miller, H. L., Cambridge University Press, Cambridge, 996 pp., 2007.

Keir, R.: Dissolution of calcite in the deep sea: Theoretical predictions for the case of uniform size particles settling into a wellmixed sediment, Am. J. Sci., 282, 193-236, 1982.

Keir, R. S.: On the late Pleistocene ocean geochemistry and circulation, Paleoceanography, 3, 413-445, doi:10.1029/PA003i004p00413, 1988.

Kelly, D. C., Zachos, J. C., Bralower, T. J., and Schellenberg, S. A.: Enhanced terrestrial weathering/runoff and surface-ocean carbonate production during the recovery stages of the PaleoceneEocene Thermal Maximum, Paleoceanography, 20, PA4023 doi:10.1029/2005PA001163, 2005.

Key, R. M., Kozyr, A., Sabine, C. L., Lee, K., Wanninkhof, R., Bullister, J., Feely, R. A., Millero, F., Mordy, C., and Peng, T.-H.: A global ocean carbon climatology: Results from GLODAP, Global Biogeochem. Cy., 18, GB4031, doi:10.1029/2004GB002247, 2004.

Köhler, P., Fischer, H., and Zeebe, R. E.: Quantitative interpretation of atmospheric carbon records over the last glacial termination, Global Biogeochem. Cy., 19, GB4020, doi:10.1029/2004GB002345, 2005.

Komar, N. and Zeebe, R. E.: Changes in oceanic calcium from enhanced weathering did not affect calcium-based proxies during the Paleocene-Eocene Thermal Maximum, Paleoceanography, 26, doi:10.1029/2010PA001979, 2011.

Kroopnick, P. M.: The distribution of ${ }^{13} \mathrm{C}$ of $\Sigma \mathrm{CO}_{2}$ in the world oceans, Deep-Sea Res. I, 32, 57-84, 1985.

Leon-Rodriguez, L. and Dickens, G. R.: Constraints on ocean acidification associated with rapid and massive carbon injections: The early Paleogene record at ocean drilling program site 1215, equatorial Pacific Ocean, Palaeogeogr., Palaeoclimatol., Palaeoecol., 298, 409-420, 2010.

Lueker, T. J., Dickson, A. G., and Keeling, C. D.: Ocean $p \mathrm{CO}_{2}$ calculated from dissolved inorganic carbon, alkalinity, and equations for $K_{1}$ and $K_{2}$ : validation based on laboratory measurements of $\mathrm{CO}_{2}$ in gas and seawater at equilibrium, Mar. Chem., 70, 105-119, 2000.

Lunt, D. J., Valdes, P. J., Dunkley-Jones, T., Ridgwell, A., Haywood, A. M., Schmidt, D. N., Marsh, R., and Maslin, M.: $\mathrm{CO}_{2-}$ driven ocean circulation changes as an amplifier of PaleoceneEocene Thermal Maximum hydrate destabilization, Geology, 38, 875-878, doi:10.1130/G31184.1, 2010.
Mayer, L. A.: Extraction of high-resolution carbonate data for palaeoclimate reconstruction, Nature, 352, 148-150, 1991.

Menard, H. W. and Smith, S. M.: Hypsometry of Ocean Basin Provinces, J. Geophys. Res., 71, 4305-4325, 1966.

Millero, F. J.: Thermodynamics of the carbon dioxide system in the oceans, Geochim. Cosmochim. Acta, 59, 661-677, 1995.

Milliman, J. D., Troy, P. J., Balch, W. M., Adams, A. K., Li, Y.H., and Mackenzie, F. T.: Biologically mediated dissolution of calcium carbonate above the chemical lysocline?, Deep-Sea Res. I, 46, 1653-1669, 1999.

Mook, W. G.: ${ }^{13} \mathrm{C}$ in atmospheric $\mathrm{CO}_{2}$, Netherlands Journal of Sea Research, 20, 211-223, 1986.

Morse, J. W. and Mackenzie, F. T.: Geochemistry of Sedimentary Carbonates, Developments in sedimentology, 48, Elsevier, Amsterdam, 707 pp., 1990.

Mucci, A.: The solubility of calcite and aragonite in seawater at various salinities, temperatures, and one atmosphere total pressure, Am. J. Sci., 283, 780-799, 1983.

Mucci, A. and Morse, J. W.: The solubility of calcite in seawater solutions of various magnesium concentration, $I_{t}=0.697 \mathrm{~m}$ at $25 \mathrm{degC}$ and one atmosphere total pressure, Geochim. Cosmochim. Acta, 48, 815-822, doi:10.1016/0016-7037(84)901030,1984

Munhoven, G. and Francois, L. M.: Glacial-interglacial variability of atmospheric $\mathrm{CO}_{2}$ due to changing continental silicate rock weathering: A model study, J. Geophys. Res., 101, 21423 21437, 1996.

Opdyke, B. N. and Walker, J. C. G.: Return of the coral reef hypothesis: Basin to shelf partitioning of $\mathrm{CaCO}_{3}$ and its effect on atmospheric $\mathrm{CO}_{2}$, Geology, 20, 733-736, doi:10.1130/00917613(1992)020<0733:ROTCRH>2.3.CO;2, 1992.

Peacock, S., Lane, E., and Restrepo, J. M.: A possible sequence of events for the generalized glacial-interglacial cycle, Global Biogeochem. Cy., 20, GB2010, doi:10.1029/2005GB002448, 2006.

Press, W. H., Flannery, B. P., Teukolsky, S. A., and Vetterling, W. T.: Numerical Recipes in C: The Art of Scientific Computing, Cambridge University, Cambridge, 1020 pp., 1992.

Ridgwell, A. J.: Glacial-interglacial perturbations in the global carbon cycle, Ph.D. thesis, Univ. of East Anglia at Norwich, UK, 2001.

Ridgwell, A. J. and Zeebe, R. E.: The role of the global carbonate cycle in the regulation and evolution of the Earth system, Earth Planet. Sci. Lett., 234, 299-315, 2005.

Sarmiento, J. L. and Toggweiler, J. R.: A new mode of the role of the oceans in determining atmospheric $P_{\mathrm{CO}_{2}}$, Nature, 308, 621624, 1984.

Shaffer, G., Malskær Olsen, S., and Pepke Pedersen, J. O.: Presentation, calibration and validation of the low-order, DCESS Earth System Model (Version 1), Geosci. Model Dev., 1, 17-51, doi:10.5194/gmd-1-17-2008, 2008.

Siegenthaler, U. and Münnich, K. O.: ${ }^{13} \mathrm{C} /{ }^{12} \mathrm{C}$ fractionation during $\mathrm{CO}_{2}$ transfer from air to sea, in: SCOPE 16 - The Global Carbon Cycle, edited by: Bolin, B., 249-257, Wiley \& Sons, New York, 1981.

Siegenthaler, U. and Wenk, T.: Rapid atmospheric $\mathrm{CO}_{2}$ variations and ocean circulation, Nature, 308, 624-626, 1984.

Sigman, D. M., McCorkle, D. C., and Martin, W. R.: The calcite lysocline as a constraint on glacial/interglacial low-latitude production changes, Global Biogeochem. Cy., 12, 409-427, 1998. 
Stephens, B. B. and Keeling, R. P.: The influence of Antarctic sea ice on glacial-interglacial $\mathrm{CO}_{2}$ variations, Nature, 404, 171-174, 2000.

Stuecker, M. F. and Zeebe, R. E.: Ocean chemistry and atmospheric $\mathrm{CO}_{2}$ sensitivity to carbon perturbations throughout the Cenozoic, Geophys. Res. Lett., 37, L03609, doi:10.1029/2009GL041436, 2010.

Sundquist, E. T.: Geologic Analogs: Their value and limitations in carbon dioxide research, in: The Changing Carbon cycle: A Global Analysis, edited by: Trabalka, J. R. and Reichle, D. E., Springer-Verlag, New York, 371-402, 1986.

Thomas, D. J., Bralower, T. J., and Jones, C. E.: Neodymium isotopic reconstruction of late Paleocene-early Eocene thermohaline circulation, Earth Planet Sci. Lett., 209, 309-322, 2003.

Toggweiler, J. R.: Variation of atmospheric $\mathrm{CO}_{2}$ by ventilation of the ocean's deepest water, Paleoceanography, 14, 571-588, 1999.

Tyrrell, T. and Zeebe, R. E.: History of carbonate ion concentration over the last 100 million years, Geochim. Cosmochim. Acta, 68, 3521-3530, 2004.

Uchikawa, J. and Zeebe, R. E.: Influence of terrestial weathering on ocean acidification and the next glacial inception, Geophys. Res. Lett., 35, L23608, doi:10.1029/2008GL035963, 2008.

Uchikawa, J. and Zeebe, R. E.: Examining possible effects of seawater $\mathrm{pH}$ decline on foraminiferal stable isotopes during the Paleocene-Eocene Thermal Maximum, Paleoceanography, 25, PA2216, doi:10.1029/2009PA001864, 2010.

Walker, J. C. G. and Kasting, J. F.: Effects of fuel and forest conservation on future levels of atmospheric carbon dioxide, Palaeogeogr. Palaeoclim. Palaeoecol., 97, 151-189, 1992.

Walker, J. C. G., Hays, P. B., and Kasting, J. F.: Negative feedback mechanism for the long-term stabilization of earth's surface temperature, J. Geophys. Res., 86, 9776-9782, 1981.

Wanninkhof, R.: Kinetic fractionation of the carbon isotopes ${ }^{13} \mathrm{C}$ and ${ }^{12} \mathrm{C}$ during transfer of $\mathrm{CO}_{2}$ from air to seawater, Tellus, 37B, 128-135, 1985.

WOA05: World Ocean Atlas 2005, NOAA Atlas NESDIS 61, Washington, DC, available at: http://www.nodc.noaa.gov/OC5/ WOA05/pr_woa05.html (last access: 21 January 2012), 2005.

Zachos, J. C., Röhl, U., S. A. Schellenberg, A. S., Hodell, D. A., Kelly, D. C., Thomas, E., M. Nicolo, I. R., Lourens, L. J., McCarren, H., and Kroon, D.: Rapid acidification of the ocean during the Paleocene-Eocene Thermal Maximum, Science, 308, 1611$1615,2005$.
Zachos, J. C., Dickens, G. R., and Zeebe, R. E.: An early Cenozoic perspective on greenhouse warming and carbon-cycle dynamics, Nature, 451, 279-283, doi:10.1038/nature06588, 2008.

Zeebe, R. E.: Modeling $\mathrm{CO}_{2}$ chemistry, $\delta^{13} \mathrm{C}$, and oxidation of organic carbon and methane in sediment porewater: Implications for paleo-proxies in benthic foraminifera, Geochim. Cosmochim. Acta, 71, 3238-3256, 2007.

Zeebe, R. E.: Where are you heading Earth? (Commentary), Nat. Geosci., 4, 416-417, 2011.

Zeebe, R. E.: History of seawater carbonate chemistry, atmospheric $\mathrm{CO}_{2}$, and ocean acidification, Annu. Rev. Earth Planet. Sci, 40, 141-165, doi:10.1146/annurev-earth-042711-105521, 2012.

Zeebe, R. E. and Caldeira, K.: Close mass balance of long-term carbon fluxes from ice-core $\mathrm{CO}_{2}$ and ocean chemistry records, Nat. Geosci., 1, 312-315, doi:10.1038/ngeo185, 2008.

Zeebe, R. E. and Ridgwell, A.: Past changes of ocean carbonate chemistry, in: Ocean Acidification, edited by: Gattuso, J.-P. and Hansson, L., Oxford University Press, 2011.

Zeebe, R. E. and Westbroek, P.: A simple model for the $\mathrm{CaCO}_{3}$ saturation state of the ocean: The "Strangelove", the "Neritan", and the "Cretan" Ocean, Geochem. Geophys. Geosyst., 4, 1104, doi:10.1029/2003GC000538, 2003.

Zeebe, R. E. and Wolf-Gladrow, D. A.: $\mathrm{CO}_{2}$ in Seawater: Equilibrium, Kinetics, Isotopes, Elsevier Oceanography Series, Amsterdam, 346 pp., 2001.

Zeebe, R. E. and Zachos, J. C.: Reversed deep-sea carbonate ion basin-gradient during Paleocene-Eocene Thermal Maximum, Paleoceanography, 22, PA3201, doi:10.1029/2006PA001395, 2007.

Zeebe, R. E., Zachos, J. C., Caldeira, K., and Tyrrell, T.: Oceans: Carbon Emissions and Acidification (in Perspectives), Science, 321, 51-52, doi:10.1126/science.1159124, 2008.

Zeebe, R. E., Zachos, J. C., and Dickens, G. R.: Carbon dioxide forcing alone insufficient to explain PalaeoceneEocene Thermal Maximum warming, Nat. Geosci., 2, 576-580, doi:10.1038/ngeo578, 2009.

Zhang, J., Quay, P. D., and Wilbur, D. O.: Carbon isotope fractionation during gas-water exchange and dissolution of $\mathrm{CO}_{2}$, Geochim. Cosmochim. Acta, 59, 107-114, 1995. 